Article

\title{
Development of Control System for Automated Manual Transmission of 45-kW Agricultural Tractor
}

\author{
Wan-Soo Kim ${ }^{1,2}{ }^{\oplus}$, Yong-Joo Kim ${ }^{1,2, *} \mathbb{D}$, Yeon-Soo Kim ${ }^{1,3, *} \mathbb{C}$, Seung-Yun Baek ${ }^{1,2}$, \\ Seung-Min Baek ${ }^{1,2}$, Dae-Hyun Lee ${ }^{1}$, Kyu-Chul Nam ${ }^{4}$, Tae-Bum Kim ${ }^{5}$ and Hyo-Jai Lee ${ }^{6}$ \\ 1 Department of Biosystems Machinery Engineering, Chungnam National University, Daejeon 34134, Korea; \\ wskim0726@gmail.com (W.-S.K.); kelpie0037@gmail.com (S.-Y.B.); bsm1104@naver.com (S.-M.B.); \\ leedh7@cnu.ac.kr (D.-H.L.) \\ 2 Department of Smart Agriculture Systems, Chungnam National University, Daejeon 34134, Korea \\ 3 Convergence Agricultural Machinery Group, Korea Institute of Industrial Technology (KITECH), \\ Gimje 54325, Korea \\ 4 Certification, Warranty, Inspection \& Standardization Team, Korea Agricultural Machinery Industry \\ Cooperative, Cheonan 31041, Korea; kc@kamico.or.kr \\ 5 Diesel service Korea Co. Ltd., Daejeon 34357, Korea; dieselservice@nate.com \\ 6 Department of Bio-industry Mechanical Engineering, Kongju National University, Yesan 32439, Korea; \\ leehjai@kongju.ac.kr \\ * $\quad$ Correspondence: babina@cnu.ac.kr (Y.-J.K.); kimtech612@gmail.com (Y.-S.K.); Tel.: +82-42-821-6716 (Y.-J.K.); \\ $+82-42-821-7870$ (Y.-S.K.)
}

Received: 11 March 2020; Accepted: 21 April 2020; Published: 23 April 2020

\begin{abstract}
This study aims to develop and evaluate an automated manual transmission (AMT) for agricultural tractors with high efficiency and high convenience by using electric actuators. An AMT system to control manual-type shuttle gearboxes and transmissions for tractors is developed by adding a shuttle shifting actuator, a clutch actuator, and a control system to a conventional manual transmission (MT). The clutch actuator is designed using an electric motor and a reduction gear. The AMT control system is developed and experimental tests are conducted to evaluate the performance of the AMT. The results of the performance of the actuator position control demonstrate that the shuttle shifting actuator and clutch actuator are controlled appropriately, achieving a maximum overshoot of less than $5 \%$ and $0 \%$, a settling time of less than $0.500 \mathrm{~s}$ and $1.50 \mathrm{~s}$, and a steady-state error of less than $1 \%$ and $1 \%$, respectively. The performance of the automatic forward and reverse control demonstrates a shift control time of less than $2.50 \mathrm{~s}$ and target revolutions per minute (RPM) reaching time of less than $3.00 \mathrm{~s}$. Thus, AMT systems for tractors can be easily developed by applying shuttle shifting actuators, clutch actuators, and a control system to conventional manual transmissions.
\end{abstract}

Keywords: automated manual transmission; agricultural tractor; electric actuator; PID control; position control

\section{Introduction}

Tractors are work machines that are used in various fields, such as agriculture, construction, and forestry, and their demand and frequency of use are expected to increase continuously [1]. In particular, agricultural tractors are vehicles that carry out agricultural work by attaching various agricultural implements, such as plows, rotators, and balers [2,3]. The international tractor market has an expected compound annual growth rate (CAGR) of 4.02\% over the forecast period of 2020-2025 [4]. Among them, the tractor market in the Asia-Pacific region accounts for about $50 \%$ of the world market.

The transmission is the most important component in determining the working efficiency among the various components of the tractor, and research into the efficiency and automation of the 
transmission has been actively conducted recently [5-8]. Tractor transmissions are generally composed of the forward and reverse (F/R) gears, range shift gear, and driving shift gear [9]; furthermore, various transmission types are applied, according to the required size and power [10]. In particular, transmissions for higher-power tractors tend to adopt a more efficient and convenient automatic transmission technology, such as continuously variable transmission (CVT) [11] or hydro-mechanical transmission (HMT) $[12,13]$. For convenience, some tractors of less than $45 \mathrm{~kW}$ use a hydrostatic transmission (HST), which is an automatic transmission [14]. However, the power transmission efficiency of an HST is about 73-75\% [15]; thus, manual transmission (MT), with higher efficiency than HSTs, is more often used. An MT consists of a gear-train, which has the advantage of a high power transmission efficiency (of about 96\%) [16]. In addition, tractor work has the characteristic of repetitive operation between the boundary points of farmland, as it performs agricultural operations in a limited area. Therefore, gear shifts for changing F/R directions frequently occur [17]. For frequent shifting, operations such as shift levers and clutch pedal operations cause inconvenience to farmers and lower work efficiency. As an alternative, in the agricultural tractor field, some studies have been carried out on using a power shuttle [18-23] or power shift [24-26] capable of automatic F/R transmission using a hydraulic system. Li et al. [26] designed and proposed an automatic gear-shifting system capable of semi-automatic shifting with power shift transmission. They studied a shifting strategy that considers the engine operating point, according to the traction load generated by tillage, which can provide a good solution for improving user-convenience. However, these hydraulic systems are less efficient compared to electrical systems, and waste arises due to the use of hydraulic oil. Therefore, it is necessary to develop a transmission with the high efficiency of manual transmission and convenience of automatic transmission.

In the automotive field, various transmissions, such as robotized transmission, electro-hydraulic manual transmission, and automated manual transmission (AMT) have been developed as alternatives that complement the disadvantages of conventional mechanical and automatic transmissions [27,28]. A robotized gearbox transmission automates the manual transmission by using an electro-hydraulic actuator, and an electro-hydraulic manual transmission performs control of the vehicle by electronically controlling the hydraulic pressure. These systems can provide higher convenience. However, the electro-hydraulic transmission system method is cumbersome, compared to the electronic actuator method, due to various factors such as oil leakage, aging of the seal, and changes of viscosity according to the oil temperature and complicated design of the control valve. AMTs are based on mechanical manual transmissions, with the addition of actuators (hydraulic or electric) to automatically control the clutch and shuttle shifting [29]. AMT systems that use actuators to automatically control MTs benefit from both the high power train efficiency of manual transmissions and the convenience of automatic transmissions [30]. In developing and applying an AMT system, a shifting performance similar to that of a general automatic transmission using a torque converter is required. Therefore, most studies on AMT systems have focused on automatic shift quality, such as fast and smooth clutch engagement [16,31,32]. In order to improve the shift quality of AMTs, it is necessary to develop a shift control technology capable of quickly shifting a conventional manual transmission. Research on the AMT shift control technology has mainly been conducted using control algorithms [4,33,34], clutch control strategies [35], and performance evaluation [36]. Some researchers have attempted to apply AMT in the field of tractors. Zhang et al. [37] proposed a tractor AMT system of the hydraulic shift system type, and conducted a study on the shift control strategy. Xu et al. [38] proposed a control system for clutch engagement of AMT tractors using Matlab/Simulink. They reported that the application of fuzzy control theory can effectively control the clutch engagement process in the AMT tractor. However, the above studies have focused only on simulation, and performance evaluation of the hardware of the actual AMT system was not performed. In order to mount the AMT system onto the tractor transmission, it is needed to perform not only simulation but also single-component experiments and automatic shifting experiments through the development of actual hardware. According to the above studies, most studies on AMTs have been conducted in the automotive field, except for some studies in agricultural tractors 
that used hydraulic actuators. This is because the actuator motor capacity in actuator and control technologies has not yet reached a level applicable to tractors, which have atypical and high load operations. Unlike automobiles, a tractor performs traction by transmitting high driving torque to the wheels, such that it uses high reduction ratios to transmit low rotational speed and high torque from the engine to transmission. Therefore, a shifting system capable of corresponding with high torque compared to an automobile is required for clutch control. From this point of view, the combination of an electric actuator and a reduction gear can provide a good solution to respond to these requirements and provide similar performance without the use of a hydraulic system. Electric actuator-based AMT tractors do not have the problems of low efficiency and complex systems associated with the use of hydraulic transmissions (e.g., power shuttle, power shift, and CVT), and can be easily mounted additionally on a conventional manual transmissions of the tractor, which contributes to providing high convenience.

The purpose of this study was to develop an AMT for agricultural tractors by adding electric actuators to conventional manual transmissions, because this system has a higher power transmission efficiency than conventional hydraulic systems and more convenience than manual transmissions. The detailed research objectives are as follows: 1) designing and developing an AMT system by adding actuators and control systems to a conventional manual transmission for shuttle shifting and clutch control; 2) designing a clutch actuator using an electric motor and reduction gear, in consideration of the diaphragm load of the clutch; and 3) evaluating of the shifting performance using an experimental test-bed.

\section{Experimental Design}

The overall experimental procedure for the development of the tractor AMT system in this study is shown in Figure 1. The development of the AMT system was performed in the order of hardware system design, control system design, simulation of control system, and performance evaluation. First, in the hardware design section, the clutch and shuttle shifting actuators-which are main components of the AMT system-are designed. The shuttle shifting actuator is operated with the disconnection of the power, while the clutch actuator is affected by a rotating power of flywheel. Thus, the performance of the AMT is more affected by the performance of the clutch actuator than the shuttle shifting actuators. In this study, the clutch actuator was designed in consideration of the required clutch force and a commercial product was selected and used as the shuttle shifting actuator. Second, proportional-integral-derivative (PID) control was used to control the position of each actuator. The optimal PID coefficients were determined through a simulation-based control response performance evaluation. As a commercial actuator-motor was used, the control system of the actuator was calibrated and developed with a focus on simulation and experiments with the actuator components, rather than dynamic model analysis. Third, the simulation program was developed to evaluate the optimal PID coefficients and evaluate the position control performance of each actuator. The optimal PID coefficients were selected considering the response performance and the simulation-based position control performance was verified by comparing the simulation results with laboratory experiments. Fourth, component experiments on the clutch and the shuttle shifting actuators were performed in the experimental test-bed. Finally, the applicability of the AMT system was confirmed through the results of the $\mathrm{F} / \mathrm{R}$ automatic shifting experiment. 


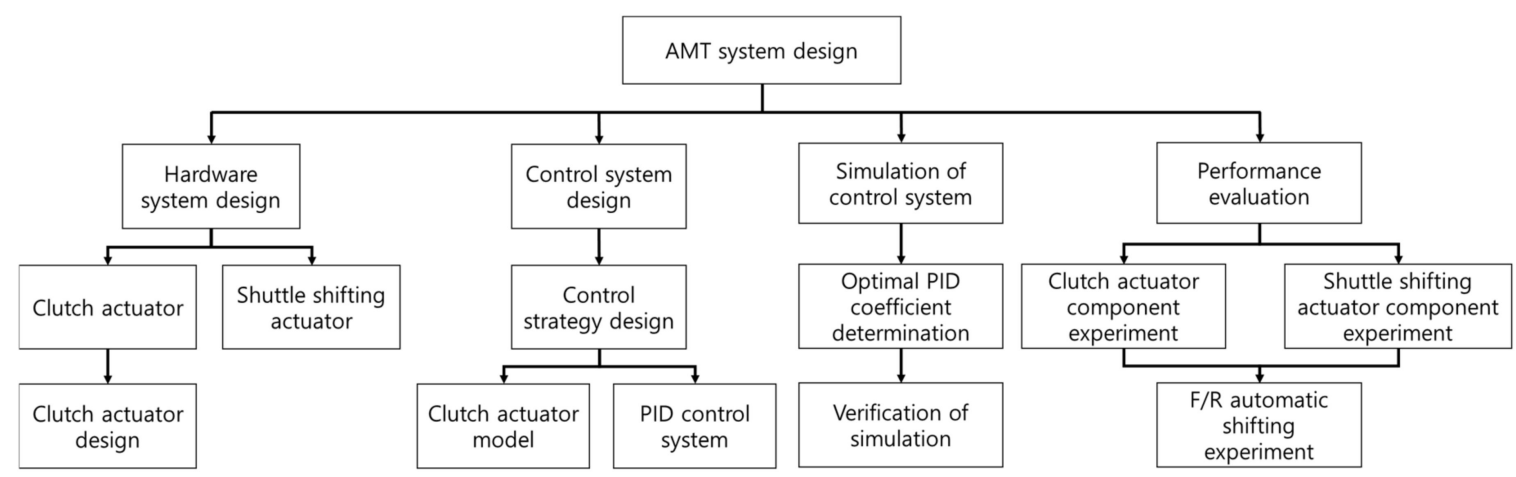

Figure 1. Overall experimental procedure for developing the proposed tractor automated manual transmission (AMT) system.

\section{Materials and Methods}

\subsection{AMT System Design}

The application of the AMT function of a tractor is an add-on method, in which an electric actuator for controlling the shuttle shifting and clutch is mounted onto a conventional manual transmission. A drawing including a shuttle shifting actuator and a clutch actuator for implementing the AMT system in this study is shown in Figure 2a. In general, there is no transmission control unit (TCU) in manual transmission tractors, but the design of the TCU is required to apply an AMT to a tractor. A tractor equipped with the AMT enables automatic shifting by installing an AMT system, including a TCU and an actuator, into its conventional manual transmission, as shown in Figure $2 b$.

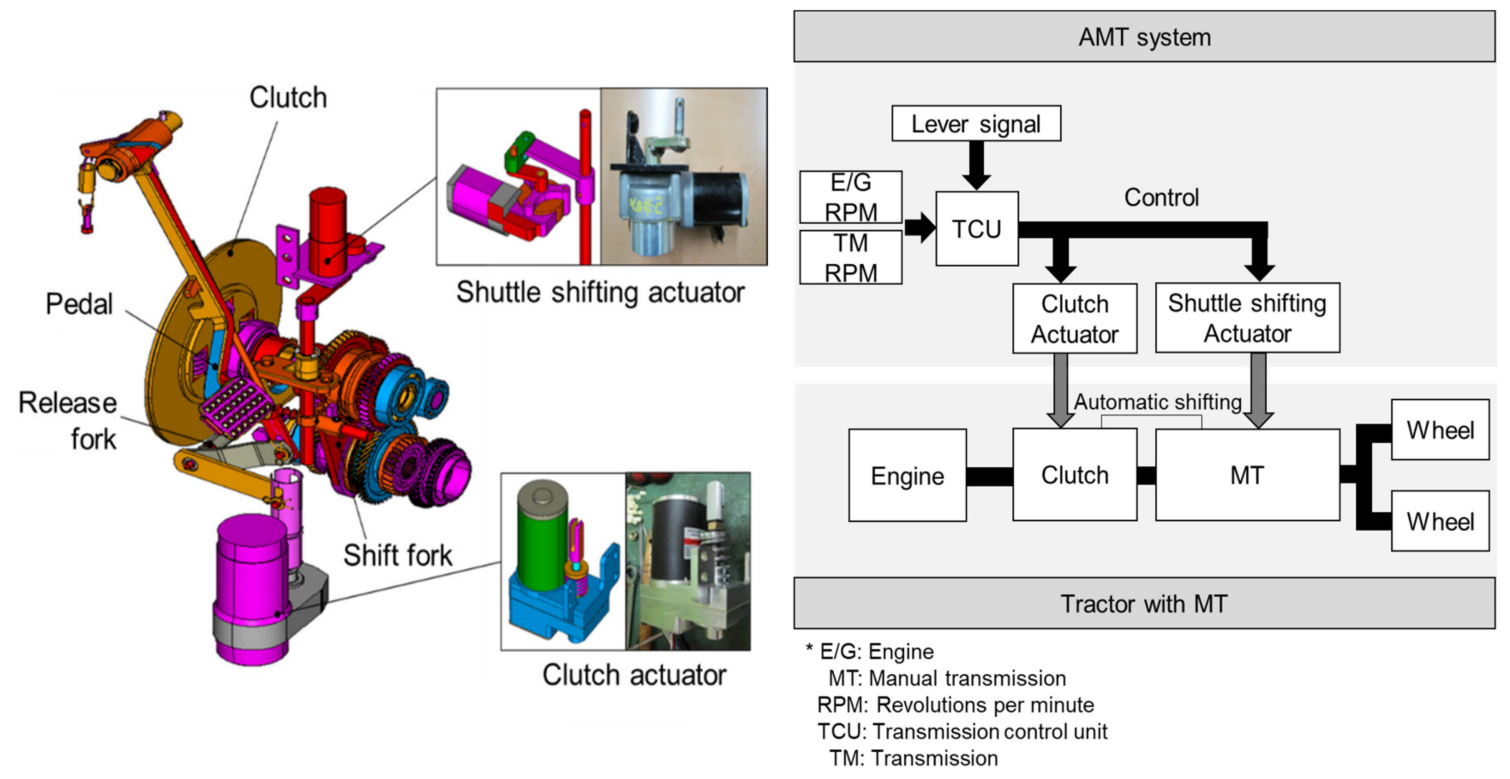

(a)

(b)

Figure 2. (a) AMT system layout including shuttle shifting actuator and clutch actuator; and (b) schematic of the AMT system combined with a manual tractor.

\subsection{Hardware System Design}

\subsubsection{Clutch Actuator}

The clutch is the main part of a tractor's powertrain, located between the engine and the transmission, which serves to transfer or disconnect the engine's power to the transmission [39]. 
The tractor used in this study is equipped with a single disc friction clutch, which is composed of components such as a release fork, release bearing, diaphragm spring, pressure plate, and clutch disc, as shown in Figure 3a. Clutch operation is largely divided into disengagement and engagement [40]. When the operator presses the clutch pedal, the central part of the diaphragm spring is pushed in the direction of the clutch disc by the release fork and release bearing. Thanks to the fulcrum ring, the outer portion of the diaphragm spring rises from the pressure disc, which causes the clutch to separate as the pressure plate is disengaged from the clutch disc. The engagement and disengagement of the clutches have opposite characteristics in the applied force and the behavior of each component. When the force applied to the pedal is removed, the pressure plate and clutch disc are connected by the elasticity force of the diaphragm spring to transfer power. A tractor AMT system automatically controls the clutch operation, instead of the operator using the clutch pedal. Therefore, to develop an AMT system, it is necessary to design and develop a clutch actuator which is suitable for the engagement and disengagement of the tractor clutch. In this study, an electronic actuator with excellent power transmission efficiency and fast control response was used, which was designed using an electric motor and reduction gear, as shown in Figure 3b, in consideration of the diaphragm load of the tractor clutch. In addition, as the engagement and disengagement of the clutch are performed by pushing or pulling the release fork connected to the clutch pedal, a screw was used to convert the rotational motion of the electric motor into linear motion. In this study, irreversible screw coupling was used so the clutch could remain in its original position when the motor was not controlled. The electric motor specification of the clutch actuator was calculated based on the force of the screw required for clutch control. The vertical force of the clutch pressure plate was $6174 \mathrm{~N}$, and the lever ratio between the clutch pressure plate and the release fork was about 0.2 . Considering a safety factor of 1.3 , the required force of the actuator was thus about $1221 \mathrm{~N}$. The input torque of the screw was calculated using the required force, screw efficiency, and screw lead based on Equation (1). The rotational speed of the actuator screw was calculated using the screw lead and screw feed rate based on Equation (2). The efficiencies of the screw and screw lead were 0.44 and $8.5 \mathrm{~mm}$, respectively. The calculated torque of the actuator screw was $3.76 \mathrm{Nm}$. The feed rate of the actuator screw was $2.16 \mathrm{~m} \cdot \mathrm{min}^{-1}$ and the input rotational speed of the actuator screw was 254 revolutions per minute (RPM). The reduction ratio and motor specifications were selected to minimize the motor size using the calculated screw input torque and rotational speed. The reduction ratio from the motor to the screw input was selected to be 19:1. The motor specifications had a rated torque of $0.21 \mathrm{Nm}$, rated rotational speed of $4826 \mathrm{RPM}$, rated voltage of $12 \mathrm{~V}$, rated current of $16 \mathrm{~A}$, and stall current of $65 \mathrm{~A}$ at the maximum torque point.

$$
\mathrm{F}_{\mathrm{s}}=\frac{2 \pi \cdot \eta \cdot \mathrm{T}_{\mathrm{s}}}{\mathrm{I}}
$$

where $F_{S}$ is the force of the actuator screw $(\mathrm{N}), \eta$ is the efficiency of the screw, $T_{S}$ is the input torque of the actuator screw $(\mathrm{Nm})$, and I is the length of the screw lead $(\mathrm{m})$.

$$
N_{s}=\frac{V_{s}}{\mathrm{I}}
$$

where $N_{s}$ is the rotational speed of actuator screw (RPM) and $V_{s}$ is the feed rate of actuator screw $\left(\mathrm{m} \cdot \mathrm{min}^{-1}\right)$. 


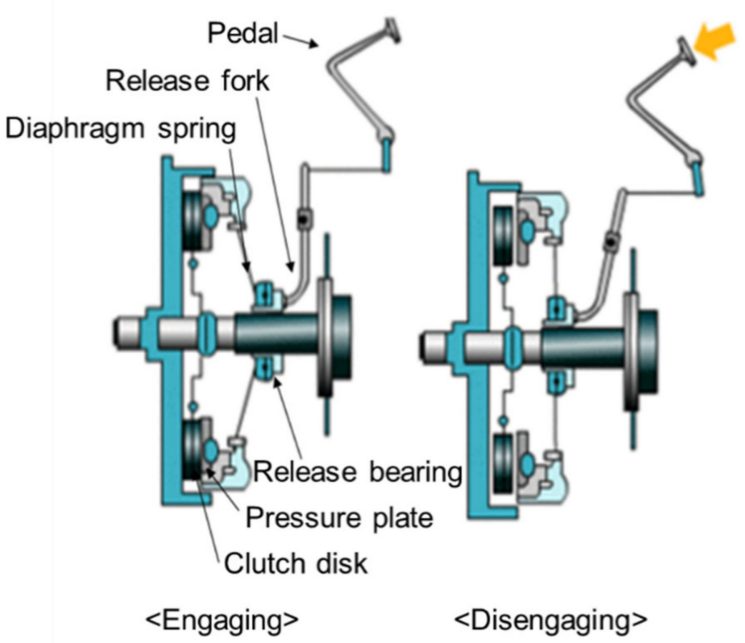

(a)

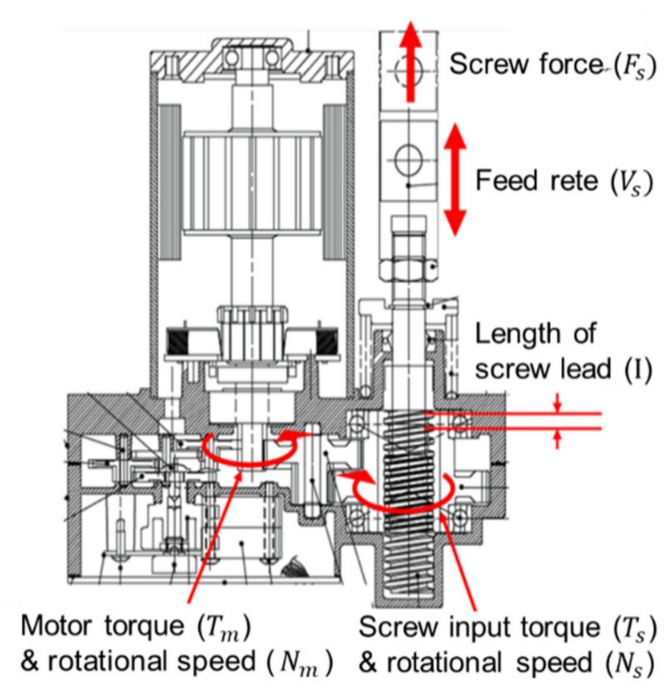

(b)

Figure 3. (a) Operating principle of a friction clutch; and (b) clutch actuator for automated clutch system.

As the clutch actuator controls the clutch through a feedback control, a potentiometer was mounted on the screw input shaft when the clutch actuator was developed, and the position of the screw could be controlled according to the rotation of the motor. The clutch was engaged at screw rising and disengaged at screw falling. The output value of the potentiometer was calibrated for screw position, and completely falling and rising were determined as 0 and $15 \mathrm{~mm}$, respectively. The ranges of engagement and disengagement were $2-4$ and $11-13 \mathrm{~mm}$, respectively, and the semi-clutching range was 9.5-10.5 mm, as shown in Figure 4a. The potentiometer ranges of the clutch actuator, as described above, were determined experimentally. The clutch actuator was controlled based on the displacement of the screw. The target positions of the screws for clutch engagement and disengagement were 12 and $3 \mathrm{~mm}$, respectively, based on the clutch position. When the clutch was connected immediately, without recognition of the starting point of the power transmission, the sudden power transmission caused user discomfort and engine stall. The clutch connection was controlled by dividing into partial engagement (half clutch), where the pressure plate begins to come into contact with the friction disc, and complete engagement, where the plate is in close contact with the power transmission. The screw target position was $10 \mathrm{~mm}$ for partially engaging control. The potentiometer mounted inside the clutch actuator was calibrated using a clutch actuator and linear variable differential transformer (LVDT). The LVDT (SAF50, HANSE PRECISION, Korea) was used to measure the displacement of the clutch actuator. The potentiometer calibration result of the clutch actuator showed a coefficient of determination of 0.99 , indicating that closed-loop control using the potentiometer of the clutch actuator is possible, as shown in Figure $4 b$. 


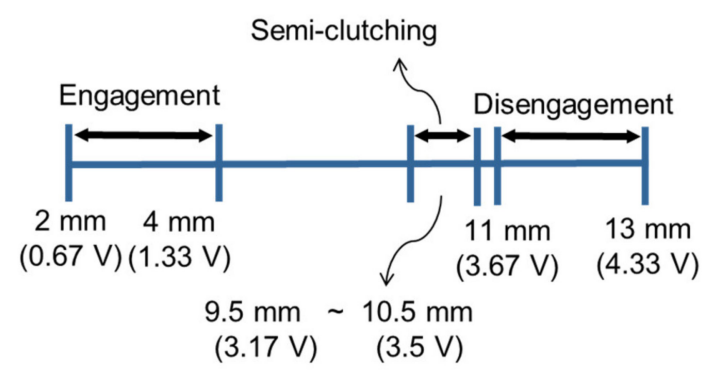

(a)

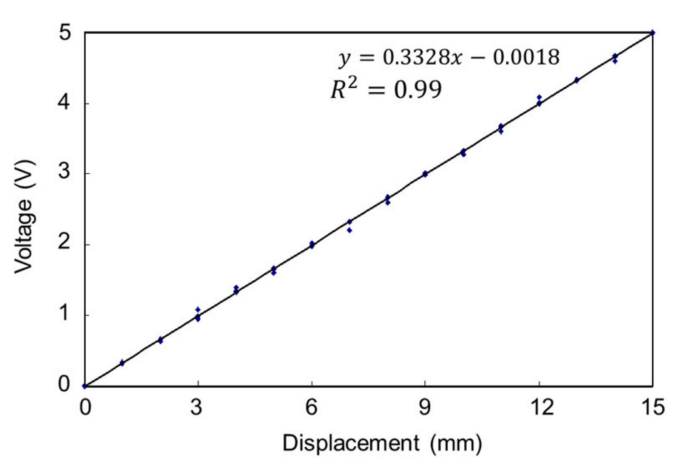

(b)

Figure 4. (a) Potentiometer values; and (b) calibration result according to position for clutch actuator.

\subsubsection{Shuttle Shifting Actuator}

In this study, a commercial actuator for shuttle transmission with a voltage of $12 \mathrm{~V}$, rated torque of $294 \mathrm{Nm}$, rotational speed of 45 RPM, and current of 5 A was used. A shuttle shifting actuator was developed to shift the shuttle gear of a synchromesh-type and connect to the shuttle linkage. The shuttle shifting actuators were controlled by an input voltage (0-12 V), and potentiometers were installed in each actuator for position control by rotation of the motors. The position ranges of the shuttle shifting actuators were decided by rotational displacement of the motors. The ranges of the shuttle shifting actuator were divided into $20^{\circ}$ intervals from $15^{\circ}$ to $75^{\circ}$ at reverse, neutral, and forward, as shown in Figure 5a. The potentiometer ranges of the shuttle shifting actuator, as described above, were determined experimentally. The potentiometer mounted inside the shuttle shifting actuator was calibrated using an external potentiometer (SP2800, Novotechnik, Germany). The potentiometer calibration result of the shuttle shifting actuator showed coefficient of determination of 0.99 , indicating that closed-loop control using the potentiometer of the shuttle shifting actuator is possible, as shown in Figure 5b.

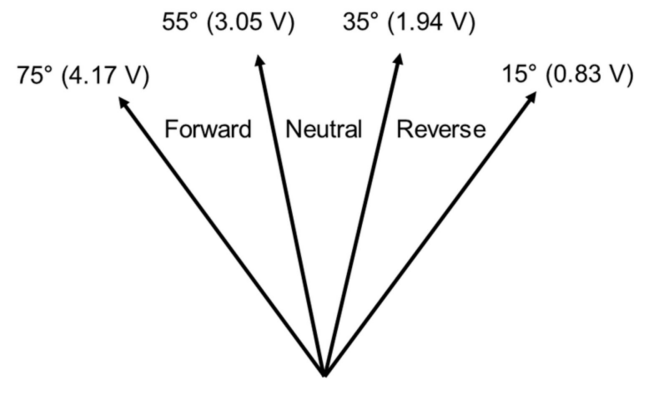

(a)

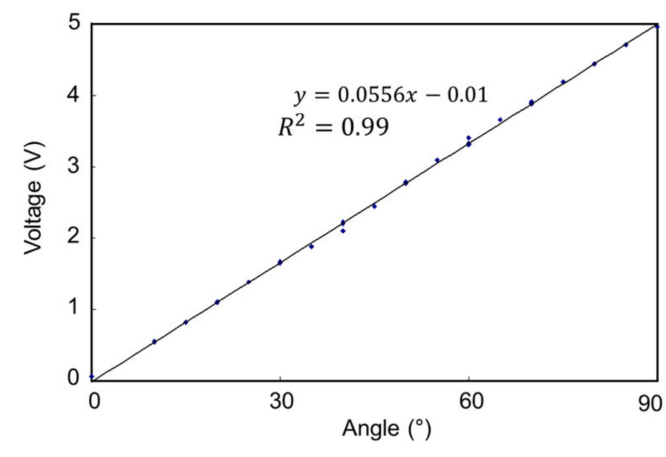

(b)

Figure 5. (a) Potentiometer values; and (b) calibration result, according to position of clutch actuator.

\subsection{Control System Design}

\subsubsection{Control Strategy}

As the AMT system performs clutch engagement and F/R shifting using electric actuators, the position control of the shuttle shifting actuator and F/R actuator control the major performance of the AMT. The position of each actuator was controlled by a slightly different method, to suit their purposes. The position control of the shuttle shifting actuator was performed such that the settling time and steady-state error were minimized, even if an overshoot occurred. In contrast, the position 
control of the clutch actuator was performed such that there was no overshoot and the settling time and steady-state error were minimal. This is because, in the case of a clutch actuator, a shift shock due to vibration should not occur. The actuator control system was developed based on PID control. As the required force for clutch and shuttle shifting actuator control was satisfied in the actuator design, the actuator control precision was realized by determining the optimal PID coefficients. The flow of the entire AMT control system, including the operation of each actuator, is shown in Figure 6. The detailed process is as follows: 1) The operator transmits the control signal to the TCU through lever operation; 2) the TCU transfers the command signals sequentially to each actuator; 3 ) the clutch actuator is actuated, disengaging the clutch; 4 ) when the clutch is disengaged, the shuttle actuator is operated and the synchronizer is moved to perform F/R shifting; 5) the clutch actuator is activated to engage the clutch.

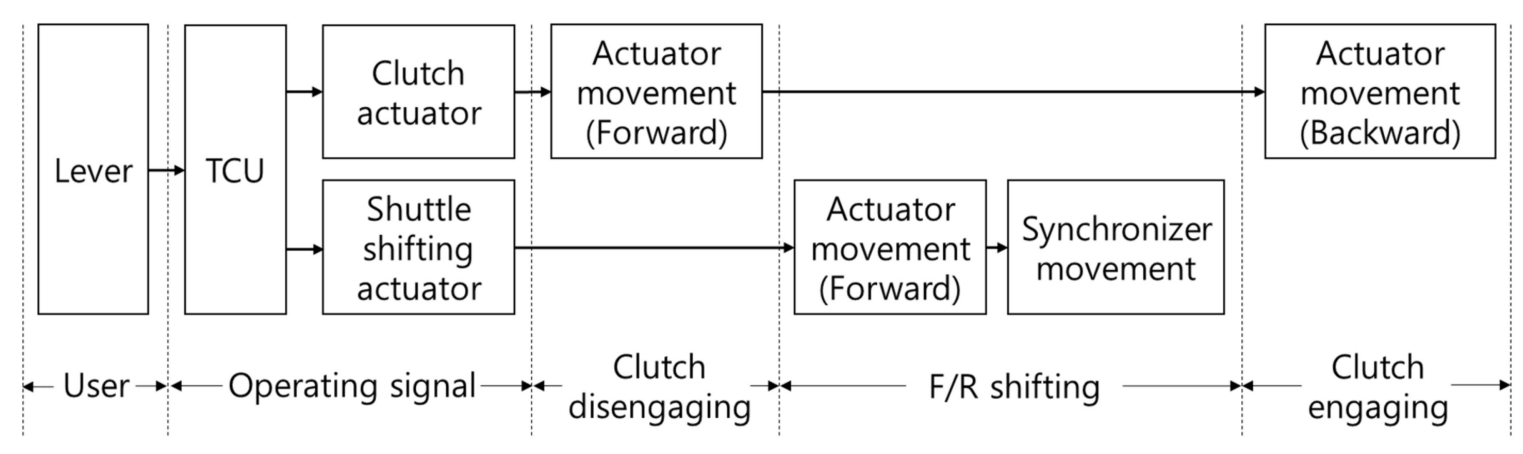

Figure 6. Control procedure of the AMT system in case of neutral to forward.

\subsubsection{Clutch and Actuator Model}

The torque capacity of the clutch was determined by considering the maximum engine torque and safety factor. The vertical force of the clutch was calculated, using the clutch torque capacity, friction coefficient, number of the plate, and clutch disc's effective radius, by the clutch model in Equations (3) and (4) [41]. Considering the engine's maximum torque of $171 \mathrm{Nm}$ and a safety factor of 2.5 , the clutch torque capacity was $427.5 \mathrm{Nm}$. The clutch disc's effective radius was calculated to be $115.4 \mathrm{~mm}$, considering the outer radius of the clutch plate as $275 \mathrm{~mm}$ and the inner radius of the clutch plate as $180 \mathrm{~mm}$. In addition, considering the two friction plates and a friction coefficient of 0.3 , the clutch vertical force was calculated to be $6174 \mathrm{~N}$.

$$
\begin{gathered}
F=\frac{T_{\mathcal{c}}}{\mu_{c} \cdot n \cdot r_{m}}, \\
r_{m}=\frac{2\left(R_{0}^{3}-R_{i}^{3}\right)}{3\left(R_{0}^{2}-R_{i}^{2}\right)^{2}},
\end{gathered}
$$

where $T_{c}$ is the clutch torque capacity $(\mathrm{Nm}), \mu_{c}$ is the friction coefficient, $n$ is the number of the plate, $F$ is the clutch vertical force $(\mathrm{N}), R_{0}$ is the outer radius of the clutch plate $(\mathrm{m}), R_{i}$ is the inner radius of the clutch plate $(\mathrm{m})$, and $r_{m}$ is the clutch disc's effective radius $(\mathrm{m})$.

The clutch actuator is connected to the release fork and diaphragm spring by a link, and the engagement and disengagement of the clutch is determined as the displacement of the clutch actuator is controlled. The dynamic model of the actuator is as shown in Equations (5) and (6), and the model for the vertical force acting on the clutch plate, according to the output force of the actuator, is shown in Equations (7)-(9) [41]. The ratio of the diaphragm and release bearing and ratio of the clutch fork lever are 0.3 and 0.5 , respectively.

$$
\begin{aligned}
& x_{r e l}=k_{C F} \cdot x_{a c t}, \\
& x_{\text {dia }}=k_{\text {dia }} \cdot x_{r e l},
\end{aligned}
$$


where $k_{\text {dia }}$ is the ratio of the diaphragm and release bearing, $k_{C F}$ is ratio of the clutch fork lever, $x_{\text {rel }}$ is the displacement of the release fork $(\mathrm{mm}), x_{a c t}$ is the displacement of the clutch actuator $(\mathrm{mm})$, and $x_{\text {dia }}$ is the displacement of the diaphragm spring $(\mathrm{mm})$.

$$
\begin{gathered}
F_{r e l}=k_{C F} \cdot F_{a c t}, \\
F_{d i a}=f_{d i a} \cdot x_{d i a}, \\
F=F_{d i a}-F_{r e l} \cdot k_{d i a},
\end{gathered}
$$

where $F_{a c t}$ is the force of the clutch actuator $(\mathrm{N}), F_{\text {dia }}$ is the force of the diaphragm $(\mathrm{N}), F_{r e l}$ is the force of the release fork $(\mathrm{N})$, and $f_{\text {dia }}$ is the coefficient of the diaphragm spring $(\mathrm{N} / \mathrm{mm})$.

\subsubsection{PID Control System}

The AMT control system for the tractor was developed using TCU hardware and a PID controller. Position control of the actuators is most important for AMT system performance [42]. A PID controller for the shuttle shifting and clutch actuators was designed. The actuator control model was developed using the transfer functions of the electric actuator, PID controller, and the potentiometer. DC motor models, as shown in Equations (10)-(12), were used for the actuators, and the PID controller used the general model shown in Equation (13). The transfer function of the potentiometer $\mathrm{H}(\mathrm{s})$ is shown in Equation (14). The potentiometer used in this study has a reference voltage $(E)$ of $5 \mathrm{~V}$ and a rotation degree of $270^{\circ} / 360^{\circ}$. As the transfer function was close to one, the transfer function was assumed to be a closed loop; therefore, the transfer function of the actuator control system is shown in Equation (15) and demonstrated in Figure 7.

$$
\begin{gathered}
\mathrm{G}(\mathrm{s})=\frac{K_{m}}{s(\tau s+1)}, \\
\tau=\frac{R_{a} J}{\left(R_{a} B+K K_{e}\right)}, \\
K_{m}=\frac{K}{\left(R_{a} B+K K_{e}\right)},
\end{gathered}
$$

where $\mathrm{G}(\mathrm{s})$ is the transfer function of the DC motor, $\tau$ is the time constant $(\mathrm{s}), R_{a}$ is the armature resistance $(\Omega), J$ is the moment of inertia of the motor $\left(\mathrm{kg} \cdot \mathrm{m}^{2}\right), B$ is the frictional constant of the motor $\left(\mathrm{kg} \cdot \mathrm{m}^{2} \cdot \mathrm{s}^{-1}\right), K$ is the motor torque constant $\left(\mathrm{Nm} \cdot \mathrm{A}^{-1}\right)$, and $K_{e}$ is the electromotive force (EMF) constant.

$$
G_{P I D}=K_{P}+K_{D} s+\frac{K_{I}}{s},
$$

where $G_{P I D}$ is the transfer function of the PID controller and $K_{P}, K_{I}$ and $K_{D}$ are the coefficients of the proportional, integral, and derivative, respectively.

$$
H(s)=\frac{E}{2 \pi N},
$$

where $H(s)$ is the transfer function of the potentiometer, $E$ is the voltage $(\mathrm{V})$, and $N$ is the rotation degree $\left({ }^{\circ}\right)$.

$$
T(s)=\frac{K_{m}\left(K_{d} s^{2}+K_{P} s+K_{I}\right)}{\tau s^{3}+\left(1+K_{m} K_{D}\right) s^{2}+K_{m} K_{P} s+K_{m} K_{I}},
$$

where $T(s)$ is the transfer function of the clutch and shuttle shifting electric actuators. 


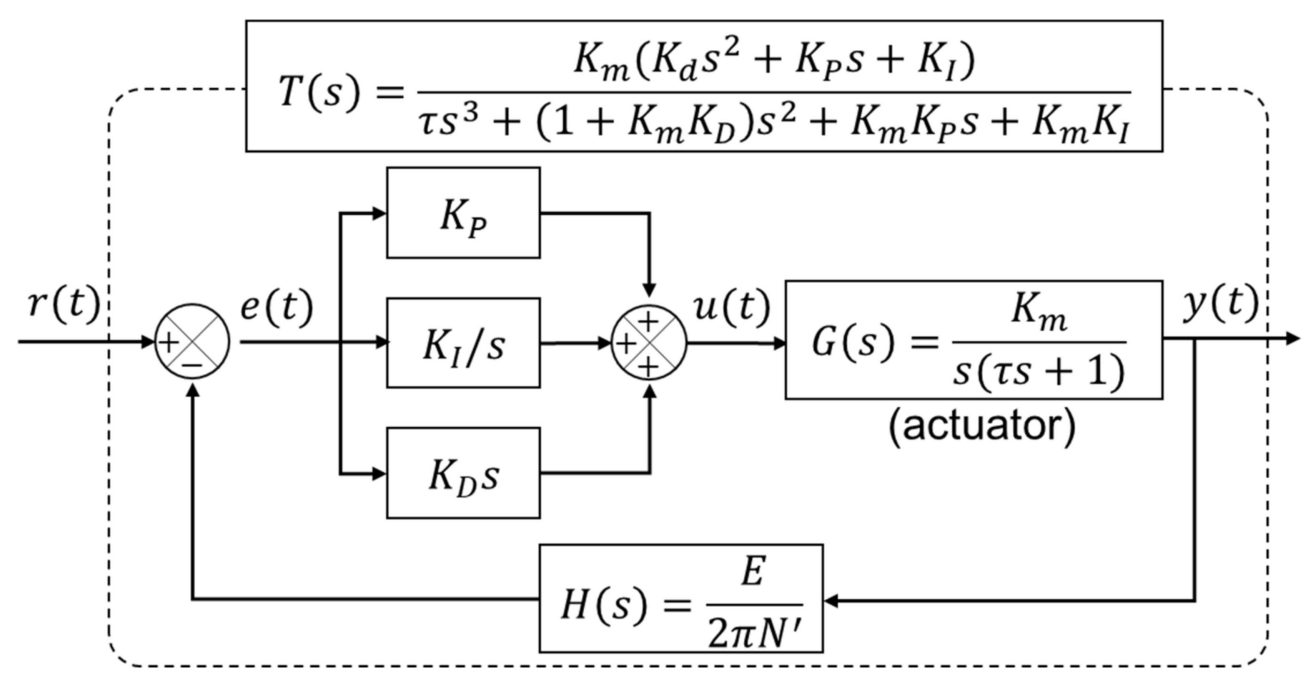

Figure 7. Block diagram of transfer function of the electric actuator system.

\subsubsection{PID Coefficient Determination}

In designing the PID controller for shuttle shifting and clutch actuator control, the determination of PID coefficients is most important [43]. The initial PID coefficients were determined using the Ziegler-Nichols (Z-N) method and Equations (16)-(18) based on the delay time $(L)$ and time constant $(\tau)$. To determine the PID coefficients, the response and stability of the system performance were analyzed, in the order of the $\mathrm{K}_{\mathrm{P}}, \mathrm{K}_{\mathrm{I}}$, and $\mathrm{K}_{\mathrm{D}}$ coefficients [30]. $\mathrm{K}_{\mathrm{P}}$ was determined by selecting an initial $K_{I}$ and $K_{D}$, and $K_{I}$ was determined using the determined $K_{P}$ and initial $K_{D}$. Finally, the $K_{D}$ coefficients were determined using the determined $K_{P}$ and $K_{I}$. Figure 8a shows the procedure of determining the PID coefficients. Lower overshoot, settling time, and steady-state error lead to better control performance parameters of the actuators. In this study, the shuttle shifting actuator was controlled by overdamping with a minimal settling time and steady-state error, regardless of overshoot. The clutch actuator was controlled by underdamping with no overshoot, as well as minimal settling time and steady-state error, as oscillation should not occur, as shown in Figure 8b. A stability evaluation was also conducted by calculating relative stability using the Nyquist stability criterion, which is one of the basic tools for stability criteria in the frequency domain using the two parameters of gain margin and phase margin. This criterion is useful for determining the stability of a feedback control system [44].

$$
\begin{gathered}
K_{P}=1.2 \frac{\tau}{L}, \\
K_{I}=\frac{K_{P}}{2 L}, \\
K_{d}=0.5 K_{P} L,
\end{gathered}
$$

where $L$ is the delay time (s). 


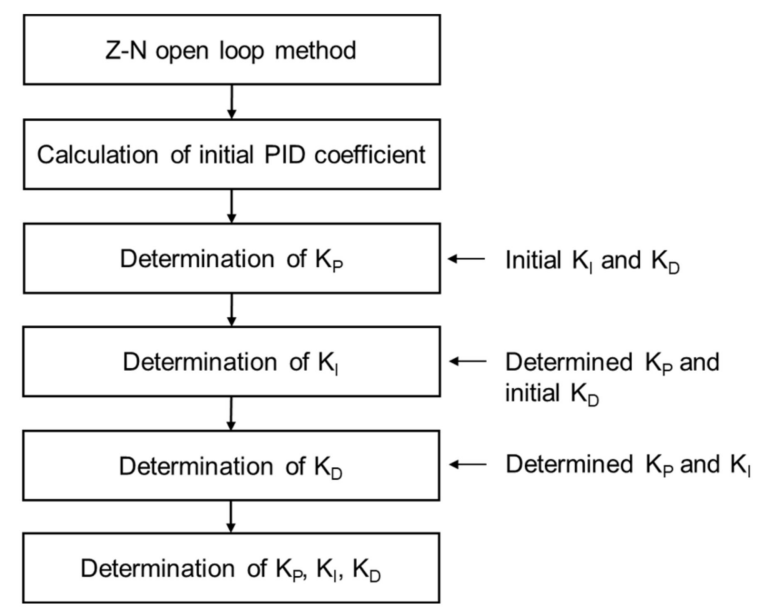

(a)

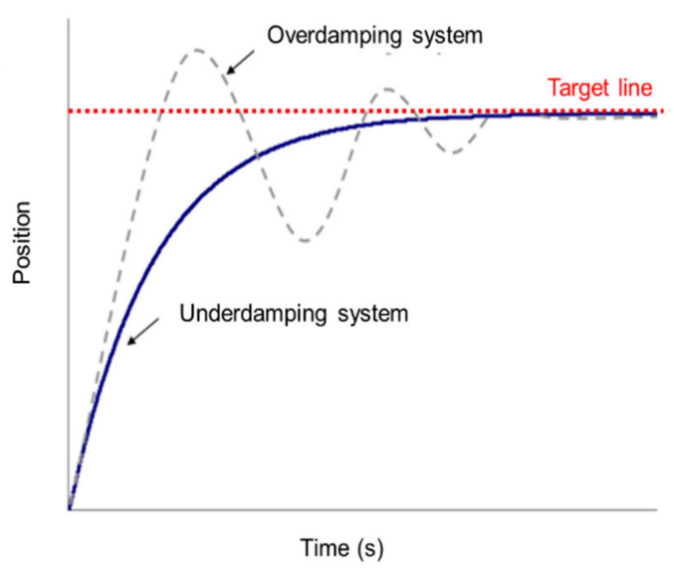

(b)

Figure 8. (a) Procedure for PID coefficient determination; and (b) position control of clutch and shuttle shifting actuator.

\subsection{Experimental Test-Bed}

In this study, the automated clutch system was developed for application in a utility tractor (U62, LS Mtron, Korea) which is mostly used for paddy farming in Korea. This tractor model was equipped with a mechanical engine with $45 \mathrm{~kW}$ power at $2500 \mathrm{RPM}$, which is the rated engine rotational speed. The specifications of the tractor were as follows: MT, four-wheel drive, dimensions of 3778 (L) $\times 1775$ $(\mathrm{W}) \times 2531(\mathrm{H}) \mathrm{mm}$, and total weight of $2296 \mathrm{~kg}$. The synchro-mesh-type manual transmission installed in the tractor comprised two direction gears, four driving shift gears, and four range shift gears. The experimental test-bed was constructed using the tractor's powertrain, clutch housing, AC motor (HS-45/2, Hyundai, Korea) instead of engine, three-phase inverter to control the motor speed, two actuators, and links, as shown in Figure 9. The motor was selected as identical to the tractor engine specification, and the rated torque and rotational speed were $175 \mathrm{Nm}$ and $2500 \mathrm{RPM}$, respectively. A magnetic proximity sensor (MP-981, ONO SOKKI, Japan) was installed to measure the rotational speed of the engine shaft and drive shaft. In addition, the pulse signals from the sensors were measured by a digital input module (NI 9401, National Instruments, USA), which is capable of bidirectional communication with a maximum clock rate of $10 \mathrm{MHz}$. An analog input module (NI 9205, National Instruments, USA) with $100 \mathrm{kS} \cdot \mathrm{s}^{-1}$ sampling rate and 16-bit resolution was used to measure the signals from the potentiometer in the actuators. A motor driver (KDD850UH, Kaesung Control LAB, Korea), which is capable of bidirectional control with a range of voltage outputs between $0-12 \mathrm{~V}$, was used to control the positions of the actuators. To control the motor driver, an analog output module (NI 9263, National Instruments, USA) capable of voltage output in the range between -10 and $10 \mathrm{~V}$ was used. Data were acquired by a data acquisition module (NI cDAQ-9172, National Instruments, USA) with a $5 \mathrm{MS} \cdot \mathrm{s}^{-1}$ sample rate. To control the actuators installed in the experimental test-bed, an automatic control program capable of controlling I/O modules was developed using LabVIEW (Version 2009, National Instruments, USA), which is capable of various signal processing functionalities, where the control period was determined at $0.200 \mathrm{~s}$. 

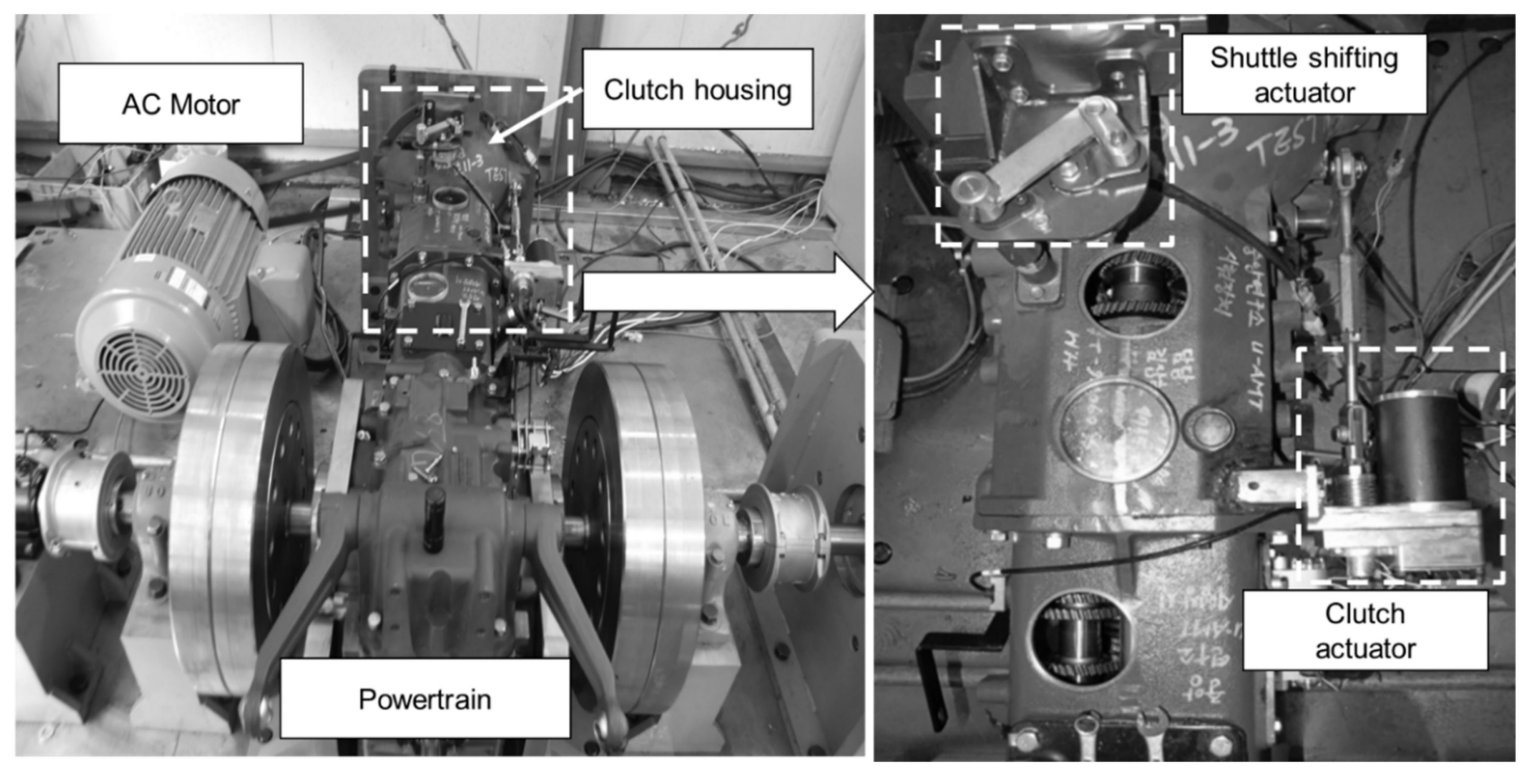

Figure 9. Experimental test-bed for AMT performance evaluation.

\subsection{Experiment Method}

\subsubsection{Simulation and Laboratory Experiment}

A simulation program was developed to determine the optimal PID coefficients, as the PID coefficients have the greatest influence on the control system performance of the clutch and shuttle shifting actuators. The optimal PID coefficients were determined for the shuttle shifting actuator and the clutch actuator, respectively, taking into account the maximum overshoot, settling time, and steady-state error, through simulation. In order to ensure the reliability of position control, according to the optimum PID coefficients, the simulation result was verified by comparison with the results of actuator control performance by laboratory experiments. Laboratory experiments were conducted to evaluate the position control performance of the actuator before mounting the actuators to the transmission.

\subsubsection{Actuator Component Performance}

The performance of the actuator was evaluated by testing component parts, such as the clutch actuator and shuttle shifting actuator, using an experimental test-bed. When the clutch was engaged, the engine torque was increased or decreased by the gear ratio determined by the transmission according to the gear stage. As the torque conditions transmitted according to the gear stage are different when the clutch was engaged or disengaged, the response characteristic of the transmission control may be different, according to the gear stage. Therefore, the performance of the position control of the shuttle shifting actuators was evaluated on the gear combination of two range-shift gears (2nd and 3rd) and four driving-shift gears (1st, 2nd, 3rd, and 4th), which is the combination of shifting gears most used for plowing in the Korea field. The experiments for the clutch actuator were performed by disengaging, partially engaging, and fully engaging the clutch when all gears of the experimental test-bed were in the neutral condition. The performance of the position control was evaluated for the step-response performance of the position of the clutch actuator screw, relative to the target position. In order to evaluate the position control performance of the shuttle shifting actuator, the transmission of the experimental test-bed was shifted in the order of neutral $\rightarrow$ forward $\rightarrow$ neutral $\rightarrow$ reverse $\rightarrow$ neutral. The target response performances of shuttle shifting actuators and clutch actuators had an overshoot of less than $5 \%$ and $0 \%$, settling times of less than 0.5 and $1.5 \mathrm{~s}$, and steady-state errors of less than $1 \%$ and $1 \%$, respectively. The experiment was repeated five times 
for each condition, and the position control performance using the determined PID coefficient was compared using the averaged response performance.

\subsubsection{F/R Automatic Shifting Performance}

The automatic shifting performance of the AMT system was evaluated through repeated tests of clutch engagement and disengagement with the shuttle shifting actuators using the experimental test-bed. For performance evaluation, the AC motor was driven at 2500 RPM and the clutch was continuously controlled for disengaging and engaging, according to each experimental condition. The performance of $\mathrm{F} / \mathrm{R}$ automatic shifting was evaluated using total duration time and RPM reaching time during shifting. The total duration time is an important factor in determining the quality of the transmission and is a main indicator in the performance evaluation of the AMT system. It was calculated by the sum of the clutch disengaging time, the shuttle shifting time, and the clutch engaging time when a gear was shifted. When a gear shifts, since the power is transmitted from the semi-clutching section and then the RPM increases, the AMT system affects the target RPM reaching time. Thus, the RPM reaching time was used as an indicator for the performance of semi-clutching of the clutch in the AMT system. Table 1 shows the calculated transmission RPM, using each gear ratio of $F / R$, at the rated engine rotational speed (2500 RPM). The calculated transmission RPM is one of the performance indicators of the AMT system, which indicates the target value that the transmission should reach when the clutch is engaged at each gear stage; this was used to analyze the RPM reaching time.

Table 1. Calculated rotational speed of transmission by each gear ratio at engine-rated rotational speed.

\begin{tabular}{ccccccccccc}
\hline \multicolumn{2}{c}{ Range shift } & \multicolumn{4}{c}{ 2nd } & \multicolumn{4}{c}{ 3rd } \\
\hline \multicolumn{2}{c}{ Driving shift } & 1st & 2nd & 3rd & 4th & 1st & 2nd & 3rd & 4th \\
\hline \multirow{2}{*}{ Rotational speed } & Forward & 66 & 79 & 93 & 124 & 147 & 174 & 205 & 276 \\
\cline { 3 - 13 } & Reverse & 55 & 65 & 76 & 102 & 121 & 143 & 168 & 225 \\
\hline
\end{tabular}

\section{Results and Discussion}

\subsection{Simulation of Control System}

\subsubsection{Initial PID Coefficients}

The initial PID coefficients were selected using the delay time and time constant based on Equations (16)-(18). The delay time and time constant of the shuttle shifting actuator were 0.137 and $0.410 \mathrm{~s}$, respectively, when gear-shifting from neutral to forward, and were 0.145 and $0.380 \mathrm{~s}$, respectively, when gear-shifting from neutral to reverse. The delay time and time constant showed similar ranges in both cases. In this study, the initial PID coefficients for the shuttle shifting actuator were selected as $K_{P}$ $=3.43, \mathrm{~K}_{\mathrm{I}}=12.25$, and $\mathrm{K}_{\mathrm{D}}=0.24$, using average values (delay time: $0.140 \mathrm{~s}$, time constant: $0.400 \mathrm{~s}$ ). The response characteristics of the potentiometer were measured assuming the $\mathrm{Z}-\mathrm{N}$ step-response to move from disengagement to engagement, in order to select the initial PID control coefficients of the clutch actuator. As the delay time and time constant were 0.190 and $0.310 \mathrm{~s}$, the initial coefficients $\mathrm{K}_{\mathrm{P}}=1.96, \mathrm{~K}_{\mathrm{I}}=5.16$, and $\mathrm{K}_{\mathrm{D}}=0.18$ were selected.

\subsubsection{Determination of Optimal PID Coefficient}

Based on the above initial PID coefficients, PID coefficients with a low overshoot, settling time, and steady-state error were determined through simulation. Table 2 shows response performances of the shuttle shifting and clutch actuators, according to the PID coefficients. To evaluate the determined PID coefficients, the response performances of the shuttle shifting actuator under the determined PID coefficients $\left(K_{P}=6.50, K_{I}=5.70\right.$, and $\left.K_{D}=0.240\right)$ and arbitrary control coefficient pairs through the developed simulation program were compared, as shown in Figure 10a. In this case, the arbitrary 
control coefficient pair indicates the optimum coefficient pair when the $K_{P}$ is set to $6.30\left(K_{P}=6.30\right.$, $K_{I}=4.80$, and $\left.K_{D}=0.155\right)$ and the optimum coefficient pair when the $K_{P}$ is set to $6.70\left(K_{P}=6.70\right.$, $K_{I}=6.05$, and $K_{D}=0.330$ ). In the case of the PID coefficients of $K_{P}=6.30, K_{I}=4.80$, and $K_{D}=0.155$, the maximum overshoot, settling time, and steady-state error were $8.50 \%, 1.18 \mathrm{~s}$, and $0 \%$, respectively. In addition, in the case of the PID coefficients of $K_{P}=6.70, K_{I}=6.05$, and $K_{D}=0.330$, the maximum overshoot, settling time, and steady-state error were $1.50 \%, 3.74 \mathrm{~s}$, and $4.5 \%$, respectively. Therefore, the PID coefficients $\left(K_{P}=6.50, K_{I}=5.70\right.$, and $\left.K_{D}=0.240\right)$ of the shuttle shifting actuator with a maximum overshoot of $3 \%$, settling time of $0.440 \mathrm{~s}$, and steady-state error of $0 \%$ were determined. To evaluate the determined PID coefficients, the response performances of the clutch actuator were compared, as shown in Figure 10b. In this case, the arbitrary control coefficient pair indicated the optimum coefficient pair when $\mathrm{K}_{\mathrm{P}}$ was set to $1.25\left(\mathrm{~K}_{\mathrm{P}}=1.25, \mathrm{~K}_{\mathrm{I}}=2.85\right.$, and $\left.\mathrm{K}_{\mathrm{D}}=0.065\right)$ and the optimum coefficient pair when $\mathrm{K}_{\mathrm{P}}$ is set to $1.65\left(\mathrm{~K}_{\mathrm{P}}=1.65, \mathrm{~K}_{\mathrm{I}}=4.15\right.$, and $\left.\mathrm{K}_{\mathrm{D}}=0.325\right)$. In the case of the PID coefficients of $K_{P}=1.25, K_{I}=2.85$, and $K_{D}=0.065$, the settling time was $2.50 \mathrm{~s}$. In addition, in the case of the PID coefficients of $\mathrm{K}_{\mathrm{P}}=1.65, \mathrm{~K}_{\mathrm{I}}=4.15$, and $\mathrm{K}_{\mathrm{D}}=0.325$, the settling time was $1.68 \mathrm{~s}$. In both cases, the control performance was lower than the settling time of $1.06 \mathrm{~s}$ and, so, the best-performing PID coefficients were $K_{P}=1.45, K_{I}=3.45$, and $K_{D}=0.190$. Therefore, as the determined PID coefficients not only satisfied the overdamping and underdamping control of the shuttle shifting and clutch actuators, respectively, but also had a small error with the target position, it was concluded that the determined PID coefficients were applicable to the automatic shift control of the clutch.

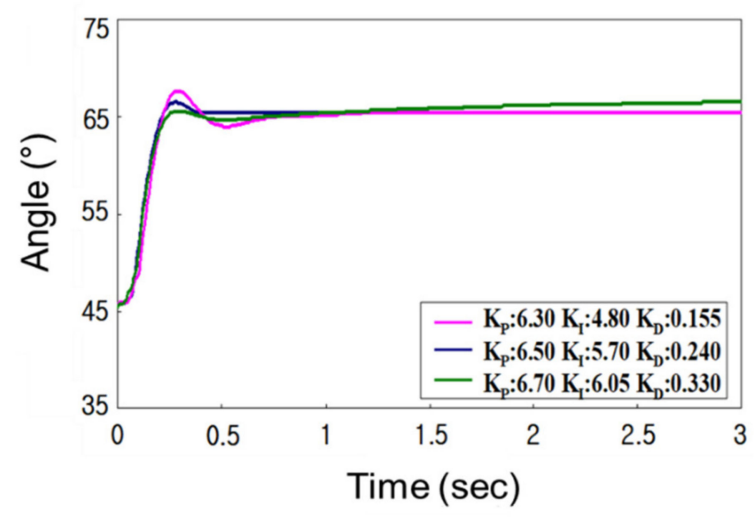

(a)

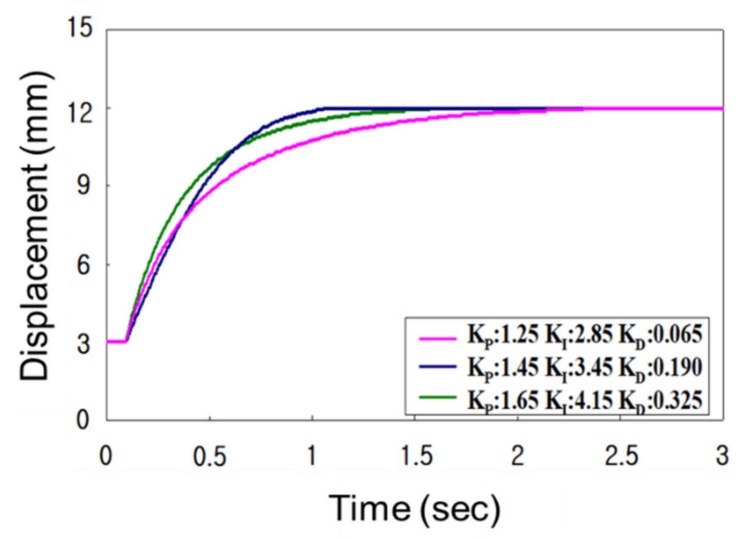

(b)

Figure 10. Comparison result of position control of (a) shuttle shifting actuator and (b) clutch actuator according to PID coefficients.

Table 2. Response performance of shuttle shifting actuator and clutch actuator according to PID coefficients.

\begin{tabular}{ccccc}
\hline \multirow{2}{*}{ Actuator } & Parameters & $\begin{array}{c}\text { Max. Overshoot } \\
\text { (\%) }\end{array}$ & $\begin{array}{c}\text { Settling Time } \\
\text { (s) }\end{array}$ & $\begin{array}{c}\text { Steady-State Error } \\
\text { (\%) }\end{array}$ \\
\hline \multirow{3}{*}{ Shuttle shifting } & $\mathrm{K}_{\mathrm{P}}=6.30, \mathrm{~K}_{\mathrm{I}}=4.80, \mathrm{~K}_{\mathrm{D}}=0.155$ & 8.50 & 1.18 & 0.00 \\
\cline { 2 - 5 } & $\mathrm{K}_{\mathrm{P}}=6.50, \mathrm{~K}_{\mathrm{I}}=5.70, \mathrm{~K}_{\mathrm{D}}=0.240$ & 3.00 & 0.44 & 0.00 \\
\cline { 2 - 5 } & $\mathrm{K}_{\mathrm{P}}=6.70, \mathrm{~K}_{\mathrm{I}}=6.05, \mathrm{~K}_{\mathrm{D}}=0.330$ & 1.50 & 3.74 & 4.50 \\
\hline \multirow{3}{*}{ Clutch } & $\mathrm{K}_{\mathrm{P}}=1.25, \mathrm{~K}_{\mathrm{I}}=2.85, \mathrm{~K}_{\mathrm{D}}=0.065$ & 0.00 & 2.50 & 0.00 \\
\cline { 2 - 5 } & $\mathrm{K}_{\mathrm{P}}=1.45, \mathrm{~K}_{\mathrm{I}}=3.45, \mathrm{~K}_{\mathrm{D}}=0.190$ & 0.00 & 1.06 & 0.00 \\
\cline { 2 - 5 } & $\mathrm{K}_{\mathrm{P}}=1.65, \mathrm{~K}_{\mathrm{I}}=4.15, \mathrm{~K}_{\mathrm{D}}=0.325$ & 0.00 & 1.68 & 0.00 \\
\hline
\end{tabular}

\subsubsection{Verification of Simulation}

The simulation results of the control performance of the actuator was verified through laboratory experiment using the optimal PID coefficients selected as a result of the simulation above. It was 
performed for shuttle shifting actuator and clutch actuator, respectively, and the results are shown in Figure 11. In both actuator cases, the response performances in the simulation and the experiment were similar. Table 3 shows the results of the comparison of response performances by simulation and experimental results of the shuttle shifting actuator and the clutch actuator. The response performance showed less than $5 \%$ difference between simulation and experiment under all conditions. Thus, it was confirmed that the developed simulation program reflected the characteristics of the actuator well, such that it can control the shuttle shifting actuator and clutch actuator.

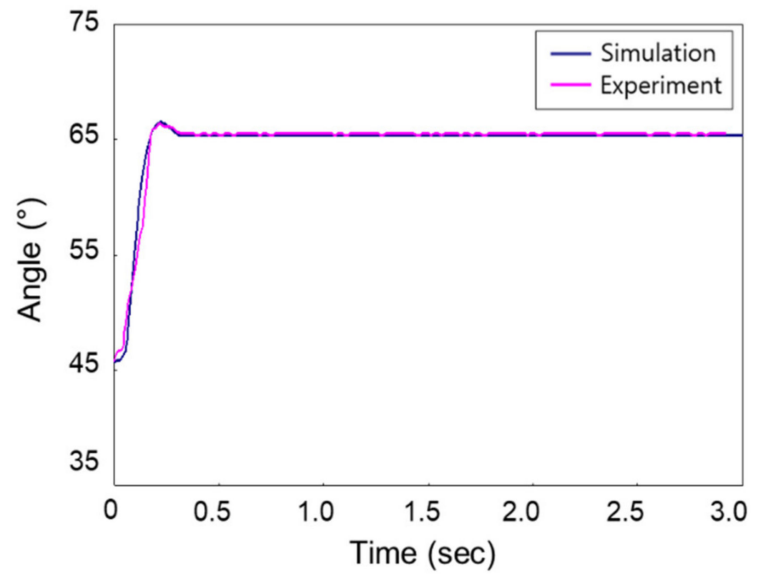

(a)

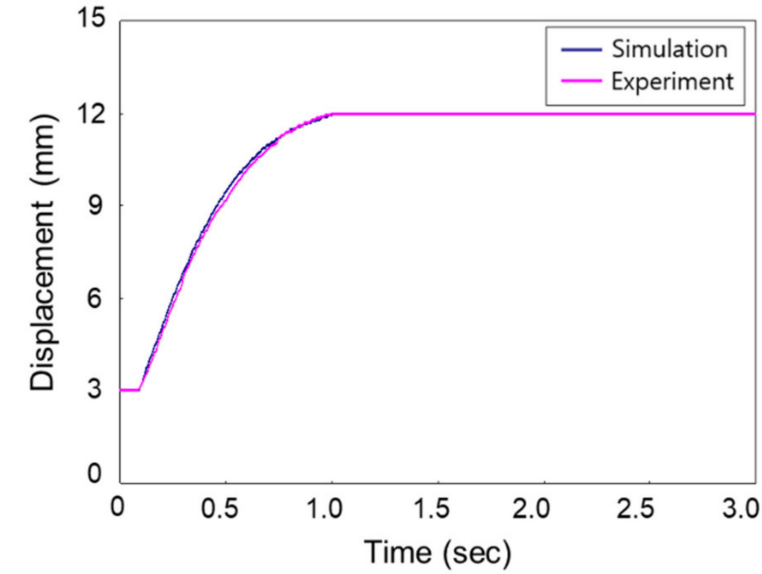

(b)

Figure 11. Comparison of simulation and component experiment results of (a) shuttle shifting actuator and (b) clutch actuator.

Table 3. Response performance in simulation and experiment for shuttle shifting and clutch actuators.

\begin{tabular}{ccccccc}
\hline \multirow{2}{*}{ Actuator } & \multicolumn{2}{c}{ Max. Overshoot (\%) } & \multicolumn{2}{c}{ Settling Time (s) } & \multicolumn{2}{c}{ Steady-State Error (\%) } \\
\cline { 2 - 7 } & Simulation & Experiment & Simulation & Experiment & Simulation & Experiment \\
\hline Shuttle shifting & 3.00 & $3.03 \pm 0.02$ & 0.44 & $0.42 \pm 0.01$ & 0.00 & $0.002 \pm 0.001$ \\
\hline Clutch & 0.00 & $0.00 \pm 0.00$ & 1.06 & $1.04 \pm 0.01$ & 0.00 & $0.002 \pm 0.001$ \\
\hline
\end{tabular}

\subsection{Performance Evaluation of Actuator Component}

\subsubsection{Clutch Actuator}

In order to evaluate the position control performance of the clutch actuator, the range shift of the transmission was set to the 2nd and then 3rd gears, and the response performance was evaluated, according to gear stages, by moving the clutch from disengaged to engaged, as shown in Figure 12 . In the entire range of gear stages, as the maximum overshoot and steady-state errors were less than $0 \%$ and $1 \%$, respectively, the target control performance was satisfied, as shown in Table 4 . The settling time of the disengaged $\rightarrow$ partially engaged (a) section was about $0.500 \mathrm{~s}$, and that of the partially engaged (a) $\rightarrow$ fully engaged (b) section was about $1.00 \mathrm{~s}$, and all showed similar results, regardless of the change in gear stages. The settling time, including disengaging $\rightarrow$ partially engaging (a) $\rightarrow$ fully engaging (b), was less than $1.50 \mathrm{~s}$ in most gear stages, which also satisfied the target control performance. 


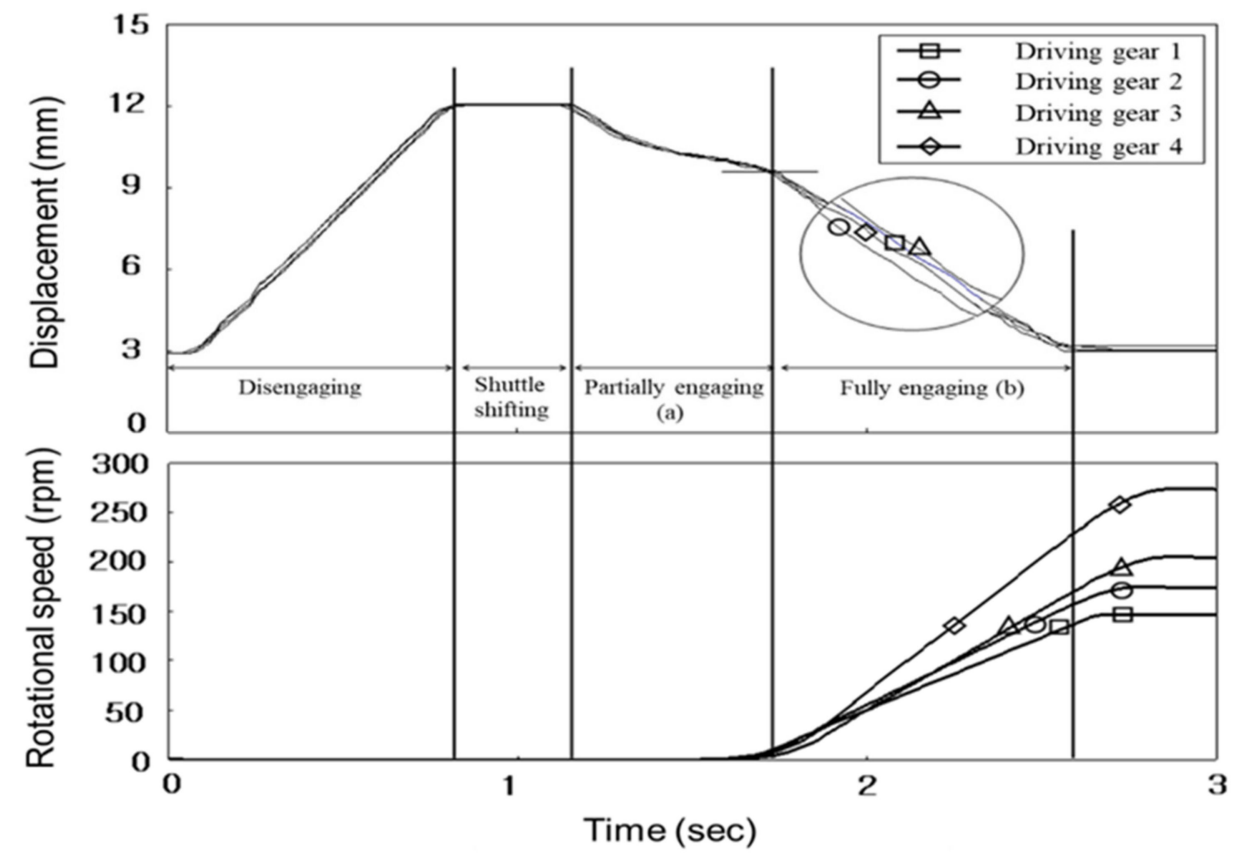

Figure 12. Position control performance of the clutch actuator according to each driving shift gear under range shift: $3 \mathrm{rd}$.

Table 4. Evaluation of shifting performance for clutch actuator according to each gear stage.

\begin{tabular}{|c|c|c|c|c|c|c|}
\hline \multirow[b]{2}{*}{ Range Shift } & \multirow[b]{2}{*}{$\begin{array}{c}\text { Driving } \\
\text { Shift }\end{array}$} & \multirow{2}{*}{$\begin{array}{c}\text { Max. } \\
\text { Overshoot } \\
(\%)\end{array}$} & \multicolumn{3}{|c|}{ Settling Time (s) } & \multirow[b]{2}{*}{$\begin{array}{c}\text { Steady-State } \\
\text { Error }(\%)\end{array}$} \\
\hline & & & $\begin{array}{l}\text { Partially } \\
\text { Engaging } \\
\text { (a) }\end{array}$ & $\begin{array}{c}\text { Fully } \\
\text { Engaging } \\
\text { (b) }\end{array}$ & $\begin{array}{c}\text { Total } \\
(a+b)\end{array}$ & \\
\hline \multirow{4}{*}{ 2nd } & 1 st & $0.00 \pm 0.00$ & $0.49 \pm 0.02$ & $0.97 \pm 0.02$ & $1.46 \pm 0.04$ & $0.14 \pm 0.028$ \\
\hline & 2nd & $0.00 \pm 0.00$ & $0.51 \pm 0.03$ & $0.92 \pm 0.02$ & $1.43 \pm 0.04$ & $0.11 \pm 0.022$ \\
\hline & $3 \mathrm{rd}$ & $0.00 \pm 0.00$ & $0.53 \pm 0.03$ & $0.93 \pm 0.01$ & $1.46 \pm 0.03$ & $0.19 \pm 0.125$ \\
\hline & 4th & $0.00 \pm 0.00$ & $0.51 \pm 0.02$ & $0.92 \pm 0.02$ & $1.43 \pm 0.04$ & $0.12 \pm 0.034$ \\
\hline \multirow{4}{*}{$3 \mathrm{rd}$} & $1 \mathrm{st}$ & $0.00 \pm 0.00$ & $0.49 \pm 0.01$ & $0.89 \pm 0.01$ & $1.37 \pm 0.02$ & $0.15 \pm 0.064$ \\
\hline & 2nd & $0.00 \pm 0.00$ & $0.50 \pm 0.02$ & $0.91 \pm 0.01$ & $1.41 \pm 0.03$ & $0.23 \pm 0.189$ \\
\hline & $3 \mathrm{rd}$ & $0.00 \pm 0.00$ & $0.50 \pm 0.02$ & $0.91 \pm 0.01$ & $1.41 \pm 0.02$ & $0.36 \pm 0.071$ \\
\hline & 4th & $0.00 \pm 0.00$ & $0.49 \pm 0.03$ & $1.00 \pm 0.01$ & $1.49 \pm 0.05$ & $0.26 \pm 0.170$ \\
\hline
\end{tabular}

\subsubsection{Shuttle Shifting Actuator}

In order to evaluate the position control performance of the shuttle shifting actuator, the response performances, such as overshoot, settling time, and steady-state error, were evaluated using the experimental test-bed shown in Figure 13. The maximum overshoot and steady-state errors were $2.58 \%$ and $0.04 \%$ when shifting from neutral to forward, and $3.11 \%$ and $0.03 \%$ when shifting from forward to neutral, respectively, as shown in Table 5 . The settling time from the neutral to forward position was $0.430 \mathrm{~s}$, and the settling time from forward to neutral was $0.370 \mathrm{~s}$. The maximum overshoot and steady-state errors were $3.36 \%$ and $0.02 \%$ when shifting from neutral to reverse, and $2.78 \%$ and $0.03 \%$ when shifting from reverse to neutral, respectively. The settling time from the neutral to reverse position was $0.400 \mathrm{~s}$, and the settling time from reverse to neutral was $0.310 \mathrm{~s}$. Although there were some differences depending on the control direction, it was found that the control of the shuttle shifting actuator was performed while satisfying the control targets of a maximum overshoot of less than $5 \%$, settling time of less than $0.500 \mathrm{~s}$, and steady-state error of less than $1 \%$. 


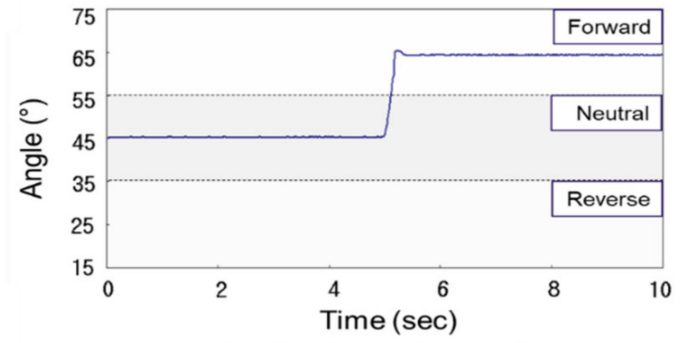

(a) Neutral $\rightarrow$ Forward

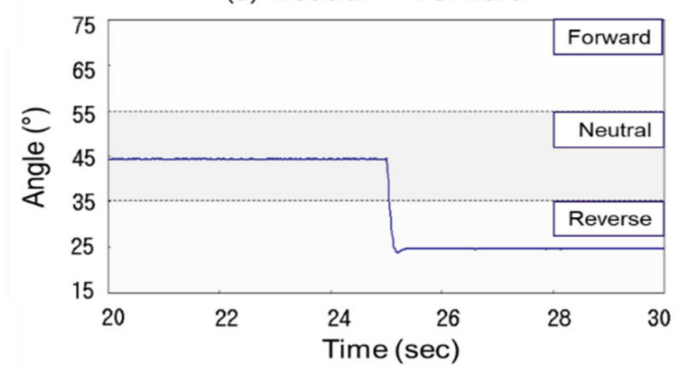

(c) Neutral $\rightarrow$ Reverse

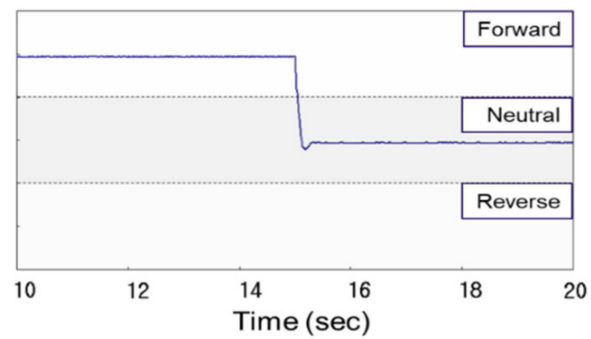

(b) Forward $\rightarrow$ Neutral

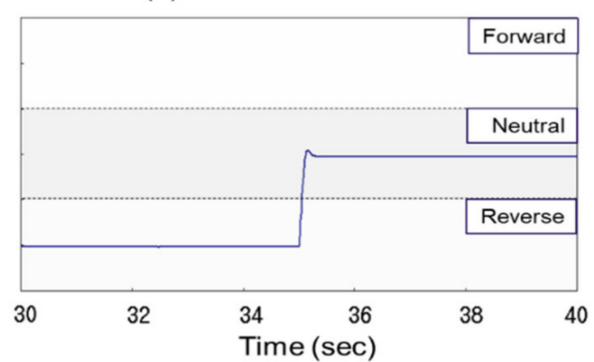

(d) Reverse $\rightarrow$ Neutral

Figure 13. Position control of shuttle shifting actuator with determined PID coefficients.

Table 5. Results of response performance analysis for the shuttle shifting actuator.

\begin{tabular}{cccc}
\hline Control Direction & Max. Overshoot (\%) & Settling Time (s) & Steady-State Error (\%) \\
\hline Neutral $\rightarrow$ Forward & $2.58 \pm 0.035$ & $0.43 \pm 0.012$ & $0.04 \pm 0.003$ \\
\hline Forward $\rightarrow$ Neutral & $3.11 \pm 0.085$ & $0.37 \pm 0.023$ & $0.03 \pm 0.005$ \\
\hline Neutral $\rightarrow$ Reverse & $3.36 \pm 0.068$ & $0.40 \pm 0.020$ & $0.02 \pm 0.010$ \\
\hline Reverse $\rightarrow$ Neutral & $2.78 \pm 0.040$ & $0.31 \pm 0.012$ & $0.03 \pm 0.005$ \\
\hline
\end{tabular}

\subsection{Performance Evaluation of $F / R$ Automatic Shifting}

The results of the performance evaluation of the F/R automatic shift control under range shift: 3rd, and driving shift: 2nd are shown in Figure 14. According to the F/R automatic shifting, the signals of the shuttle shifting and the clutch actuators satisfied the shift range for all cases of forward, neutral, and reverse. For automatic shuttle shifting control from neutral to forward and from neutral to reverse, the response performance is shown in Table 6. The response performance was not affected by the gear stages. The performance of total duration time and RPM reaching time was higher in neutral $\rightarrow$ reverse than neutral $\rightarrow$ forward under the same gear stage. In all cases of neutral $\rightarrow$ forward and neutral $\rightarrow$ reverse, the total duration time was within $2.50 \mathrm{~s}$, regardless of the gear stage, and the target RPM reaching time was within $3.00 \mathrm{~s}$. In the case of forward $\rightarrow$ neutral and reverse $\rightarrow$ neutral, motor power was not transmitted to the transmission. Thus, this case was excluded from the measurement. The total duration time (i.e., shifting time) of the developed AMT system was confirmed to be applicable by comparing with the results of previous studies; for example, AMT in an automotive car achieved $2.62 \mathrm{~s}$ [35]; power shift, $3.00 \mathrm{~s}$ [21]; and power shuttle, $2.90 \mathrm{~s}$ [20]. 


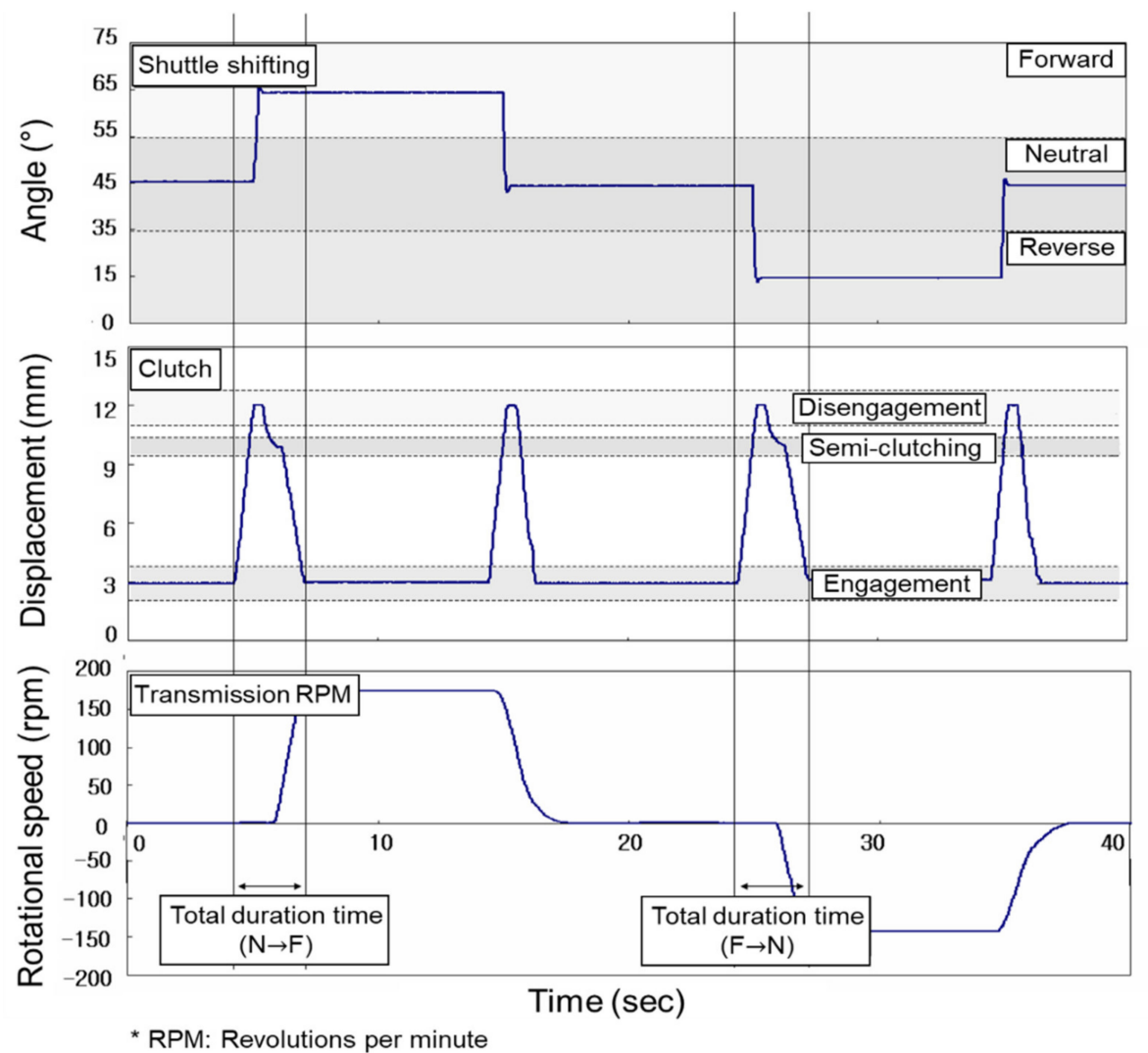

Figure 14. Results of automatic shuttle shifting control (range shift: 3rd, driving shift: 2nd).

Table 6. Results of performance evaluation for automatic shuttle shifting control according to shifting conditions and each gear stage.

\begin{tabular}{|c|c|c|c|c|c|}
\hline $\begin{array}{l}\text { Shifting } \\
\text { Condition }\end{array}$ & Range Shift & Driving Shift & $\begin{array}{l}\text { Total Duration } \\
\text { Time (s) }\end{array}$ & $\begin{array}{l}\text { RPM Reaching } \\
\text { Time (s) }\end{array}$ & $\begin{array}{c}\text { Transmission RPM } \\
(\text { (rpm) }\end{array}$ \\
\hline \multirow{8}{*}{$\begin{array}{l}\text { Neutral } \\
\stackrel{\rightarrow}{\text { Forward }}\end{array}$} & \multirow{4}{*}{ 2nd } & $1 \mathrm{st}$ & $2.40 \pm 0.04$ & $2.63 \pm 0.05$ & $66.3 \pm 0.05$ \\
\hline & & 2nd & $2.35 \pm 0.05$ & $2.59 \pm 0.04$ & $79.1 \pm 0.10$ \\
\hline & & $3 r d$ & $2.40 \pm 0.04$ & $2.65 \pm 0.03$ & $93.1 \pm 0.13$ \\
\hline & & 4th & $2.38 \pm 0.07$ & $2.65 \pm 0.08$ & $124.1 \pm 0.15$ \\
\hline & \multirow{4}{*}{$3 r d$} & $1 \mathrm{st}$ & $2.29 \pm 0.03$ & $2.62 \pm 0.04$ & $147.1 \pm 0.03$ \\
\hline & & 2nd & $2.36 \pm 0.03$ & $2.69 \pm 0.03$ & $174.0 \pm 0.20$ \\
\hline & & 3rd & $2.37 \pm 0.03$ & $2.75 \pm 0.03$ & $204.8 \pm 0.25$ \\
\hline & & 4th & $2.43 \pm 0.06$ & $2.88 \pm 0.05$ & $274.0 \pm 0.22$ \\
\hline \multirow{8}{*}{$\begin{array}{l}\text { Neutral } \\
\rightarrow \\
\text { Reverse }\end{array}$} & \multirow{4}{*}{ 2nd } & $1 \mathrm{st}$ & $2.39 \pm 0.05$ & $2.61 \pm 0.08$ & $55.0 \pm 0.15$ \\
\hline & & 2nd & $2.33 \pm 0.06$ & $2.55 \pm 0.06$ & $65.0 \pm 0.10$ \\
\hline & & $3 \mathrm{rd}$ & $2.38 \pm 0.04$ & $2.60 \pm 0.03$ & $75.8 \pm 0.65$ \\
\hline & & 4 th & $2.37 \pm 0.06$ & $2.63 \pm 0.08$ & $102.0 \pm 0.06$ \\
\hline & \multirow{4}{*}{$3 \mathrm{rd}$} & 1 st & $2.29 \pm 0.04$ & $2.58 \pm 0.03$ & $121.6 \pm 0.47$ \\
\hline & & 2nd & $2.36 \pm 0.03$ & $2.63 \pm 0.03$ & $143.6 \pm 0.32$ \\
\hline & & $3 \mathrm{rd}$ & $2.37 \pm 0.04$ & $2.73 \pm 0.05$ & $168.2 \pm 0.36$ \\
\hline & & 4th & $2.41 \pm 0.03$ & $2.81 \pm 0.05$ & $225.1 \pm 0.30$ \\
\hline
\end{tabular}

\section{Conclusions}

This study was conducted to develop an automated manual transmission for agricultural tractors. Shuttle shifting and clutch actuators, which are of the electric type, were designed for the automation 
of shuttle shift and clutch control. An AMT control system for the tractor was developed using TCU hardware and a PID controller. For the PID controller design, the PID coefficients were determined by using the $\mathrm{Z}-\mathrm{N}$ method and simulation tests. An experimental test-bed for performance evaluation of the AMT was constructed using a tractor powertrain, clutch housing, a motor (instead of an engine), a three-phase inverter to control the motor speed, and two actuators. The experimental tests were conducted by shifting gear level. In order to evaluate the performance of the AMT for agricultural tractors, the transmission of the experimental test-bed was shifted from the neutral to forward and from neutral to reverse in all gear stages. The PID coefficient combination of $K_{P}=1.45, K_{I}=3.45$, and $K_{D}=0.190$ was chosen because it showed low overshoot, settling time, and steady-state error. The results of the performance of the actuator position control indicated that the shuttle shifting actuator was controlled appropriately to achieve a maximum overshoot of less than $5 \%$, settling time of less than $0.500 \mathrm{~s}$, and steady-state error of less than $1 \%$. In the case of the clutch actuator, it was controlled appropriately to achieve a maximum overshoot of less than $0 \%$, settling time of less than $1.50 \mathrm{~s}$, and steady-state error of less than $1 \%$. The automatic F/R control performance showed a shift control time of less than $2.50 \mathrm{~s}$ and target RPM reaching time of less than $3.00 \mathrm{~s}$ under all conditions (i.e., gear stages and F/R). The results showed that the developed shuttle shifting transmission control algorithm could be useful for agricultural tractor AMT. The developed system can be used for tractors with manual transmissions, and can provide high transmission power efficiency and high convenience through the automation of the transmission using the proposed control system and actuators. Farmers can use the developed system to conveniently perform shifting with a simple lever operation, instead of the series of processes (clutch press-> gear shift- $>$ clutch press release) that occur when using a conventional manual transmission. In addition, agricultural machinery companies can launch tractors with automatic transmission-level performance by adding the AMT system onto the conventional manual transmissions. As it uses a low-price electric actuator and a controller, it can be implemented inexpensively, compared to a conventional hydraulic power shuttle and power shift, which feature complex systems, in terms of price.

However, this study has some limitations: it focused only on the transmission, which is a single component and not the entire tractor. Therefore, a future study will explore simultaneously considering the shift time and the shift shock, according to the weight of the tractor. This can contribute to the development of automation systems for agricultural machinery, and it is believed that it will contribute to reducing the fatigue of operators and improving work efficiency.

Author Contributions: Conceptualization, W.-S.K. and Y.-J.K.; Methodology, D.-H.L. and Y.-S.K.; Software, D.-H.L. and W.-S.K.; Formal analysis, S.-Y.B., S.-M.B. and Y.-S.K.; Investigation, K.-C.N., T.-B.K. and H.-J.L.; Writing-Original draft preparation, W.-S.K.; Writing-Review and editing, W.-S.K.; Supervision, Y.-J.K.; Project administration, Y.-J.K. All authors have read and agreed to the published version of the manuscript.

Funding: This research was supported by the Agricultural, Forestry, Food Research Center Support Program (Project No.: 714002-07), Ministry of Agricultural, Food and Rural Affairs. It was also supported by the Korea Institute of Planning and Evaluation for Technology in Food, Agriculture, Forestry (IPET) through the Advanced Production Technology Development Program, funded by the Ministry of Agriculture, Food and Rural Affairs (MAFRA) (318095-03).

Conflicts of Interest: The authors declare no conflicts of interest.

\section{References}

1. Kim, W.S.; Kim, Y.J.; Park, S.U.; Hong, S.J.; Kim, Y.S. Evaluation of PTO severeness for 78 kW-class tractor according to disk plow tillage and rotary tillage. J. Drive Control 2019, 16, 23-31.

2. Kim, W.S.; Baek, S.Y.; Kim, T.J.; Kim, Y.S.; Park, S.U.; Choi, C.H.; Hong, S.J.; Kim, Y.J. Work load analysis for determination of the reduction gear ratio for a $78 \mathrm{~kW}$ all wheel drive electric tractor design. Korean J. Agric. Sci. 2019, 46, 613-627.

3. Islam, N.; Iqbal, Z.; Kabir, S.N.; Jung, K.Y.; Mun, D.H.; Chung, S.O. Performance evaluation of trenchless subsurface drainage piping machine. J. Biosyst. Eng. 2019, 44, 218-225. [CrossRef] 
4. Mordor Intelligence. Uility Tractors Market-Growth, Trends, and Forecast (2020-2025); Mordor Intelligence: Hyderabad, India, 2020; Available online: https://www.mordorintelligence.com/industry-reports/ utility-tractor-markethttps://www.mordorintelligence.com/industry-reports/india-agricultural-tractormachinery-market (accessed on 23 April 2020).

5. Jang, J.H.; Kim, W.S.; Choi, C.H.; Park, S.U.; Kim, Y.J. Analysis of power requirement of the underground crop harvester attached on agricultural tractor during traction operation. Korea Inf. Electron. Commun. Technol. 2018, 11, 150-155.

6. Rossetti, A.; Macor, A. Control strategies for a powertrain with hydromechanical transmission. Energy Procedia 2018, 148, 978-985. [CrossRef]

7. Kim, W.S.; Kim, Y.S.; Kim, T.J.; Park, S.U.; Choi, Y.; Choi, I.S.; Kim, Y.K.; Kim, Y.J. Analysis of power requirement of $78 \mathrm{~kW}$ class agricultural tractor according to the major field operation. Trans. Korean Soc. Mech. Eng. A 2019, 43, 911-922. [CrossRef]

8. Lee, N.G.; Kim, Y.J.; Kim, W.S.; Kim, Y.S.; Kim, T.J.; Baek, S.M.; Choi, Y.; Kim, Y.K.; Choi, I.S. Study on the improvement of transmission error and tooth load distribution using micro-geometry of compound planetary gear reducer for tractor final driving shaft. J. Drive Control 2020, 17, 1-12.

9. Kim, T.J.; Kim, W.S.; Kim, Y.S.; Chung, S.O.; Park, S.U.; Hong, S.J.; Choi, C.H.; Kim, Y.J. Strength analysis of mechanical transmission using equivalent torque of plow tillage of an $82 \mathrm{~kW}$-class tractor. Korean J. Agric. Sci. 2019, 46, 723-735.

10. İnce, E.; Güler, M.A. On the advantages of the new power-split infinitely variable transmission over conventional mechanical transmissions based on fuel consumption analysis. J. Clean. Prod. 2020, 244, 118795. [CrossRef]

11. Wang, G.; Song, Y.; Wang, J.; Chen, W.; Cao, Y.; Wang, J. Study on the shifting quality of the CVT tractor under hydraulic system failure. Appl. Sci. 2020, 10, 681. [CrossRef]

12. Janulevičius, A.; Giedra, K. Analysis of main dynamic parameters of split power transmission. Transport 2008, 23, 112-118. [CrossRef]

13. Xia, Y.; Sun, D.; Qin, D.; Zhou, X. Optimisation of the power-cycle hydro-mechanical parameters in a continuously variable transmission designed for agricultural tractors. Biosyst. Eng. 2020, 193, 12-24. [CrossRef]

14. Kim, D.M.; Kim, S.C.; Noh, D.K.; Jang, J.S. Jerk phenomenon of the hydrostatic transmission through the experiment and analysis. Int. J. Automot. Technol. 2015, 16, 783-790. [CrossRef]

15. Renius, K.T.; Resch, R. Continuously variable transmissions. In Proceedings of the 2005 Agricultural Equipment Technology Conference, Louisville, Kentucky, USA, 14-16 February 2005; Volume 29, pp. 1-37.

16. Galvagno, E.; Velardocchia, M.; Vigliani, A. Analysis and simulation of a torque assist automated manual transmission. Mech. Syst. Signal Process. 2011, 25, 1877-1886. [CrossRef]

17. Kim, Y.J.; Chung, S.O.; Choi, C.H. Effects of gear selection of an agricultural tractor on transmission and PTO load during rotary tillage. Soil Tillage Res. 2013, 134, 90-96. [CrossRef]

18. Li, C.; Ke, M.; Wu, Y. Research and implementation of tractor power shift clutch control system. In Proceedings of the MATEC Web of Conferences, Kuala Lumpur, Malaysia, 28-30 February 2017; Volume 153, p. 04003.

19. Xu, L.Y.; Zhang, Y.H.; Shi, J.Z.; Yan, X.H. Optimization of power shift tractor clutch based on ahp and improved genetic algorithm. Acta Tech. 2017, 62, 373-384.

20. Raikwar, S.; Tewari, V.K.; Mukhopadhyay, S.; Verma, C.R.B.; Rao, M. Simulation of components of a power shuttle transmission system for an agricultural tractor. Comput. Electron. Agric. 2015, 114, 114-124. [CrossRef]

21. Tanelli, M.; Panzani, G.; Savaresi, S.M.; Pirola, C. Transmission control for power-shift agricultural tractors: Design and end-of-line automatic tuning. Mechatronics 2011, 21, 285-297.

22. Kim, D.C.; Kim, K.U.; Park, Y.J.; Huh, J.Y. Analysis of shifting performance of power shuttle transmission. J. Terramech. 2007, 44, 111-122. [CrossRef]

23. Molari, G.; Sedoni, E. Experimental evaluation of power losses in a power-shift agricultural tractor transmission. Biosyst. Eng. 2008, 100, 177-183. [CrossRef]

24. Li, B.; Sun, D.; Hu, M.; Zhou, X.; Liu, J.; Wang, D. Coordinated control of gear shifting process with multiple clutches for power-shift transmission. Mech. Mach. Theory 2019, 140, 274-291. [CrossRef]

25. Li, B.; Sun, D.; Hu, M.; Liu, J. Research on economic comprehensive control strategies of tractor-planter combinations in planting, including gear-shift and cruise control. Energies 2018, 11. [CrossRef] 
26. Li, B.; Sun, D.; Hu, M.; Zhou, X.; Wang, D.; Xia, Y.; You, Y. Automatic gear-shifting strategy for fuel saving by tractors based on real-time identification of draught force characteristics. Biosyst. Eng. 2020, 193, 46-61. [CrossRef]

27. Zhao, M.; Shi, J.; Lin, C.; Zhang, J. Application-oriented optimal shift schedule extraction for a dual-motor electric bus with automated manual transmission. Energies 2018, 11, 325. [CrossRef]

28. Carbone, G.; Mangialardi, L.; Mantriota, G. Fuel consumption of a mid class vehicle with infinitely variable transmission. SAE Int. J. Engines 2001, 110, 2474-2483.

29. Li, L.; He, K.; Wang, X.; Liu, Y. Sensor fault-tolerant control for gear-shifting engaging process of automated manual transmission. Mech. Syst. Signal Process. 2018, 99, 790-804. [CrossRef]

30. Choi, C.H.; Woo, M.N.; Lee, D.H.; Kim, Y.J.; Jeong, J.H. Development of electric actuator position control system for automatic shuttle shifting of tractor. J. Biosyst. Eng. 2010, 35, 224-230. [CrossRef]

31. Van Berkel, K.; Hofman, T.; Serrarens, A.; Steinbuch, M. Fast and smooth clutch engagement control for dual-clutch transmissions. Control Eng. Pract. 2014, 22, 57-68. [CrossRef]

32. Sun, Z.; Gao, B.; Jin, J.; Sanada, K. Modelling, analysis and simulation of a novel automated manual transmission with gearshift assistant mechanism. Int. J. Automot. Technol. 2019, 20, 885-895. [CrossRef]

33. Gao, B.Z.; Chen, H.; Sanada, K.; Hu, Y. Design of clutch-slip controller for automatic transmission using backstepping. IEEE/ASME Trans. Mechatron. 2011, 16, 498-508. [CrossRef]

34. Hu, Y.; Tian, L.; Gao, B.; Chen, H. Nonlinear gearshifts control of dual-clutch transmissions during inertia phase. ISA Trans. 2014, 53, 1320-1331. [CrossRef] [PubMed]

35. Glielmo, L.; Iannelli, L.; Vacca, V.; Vasca, F. Gear shift control for automated manual transmissions. IEEE/ASME Trans. Mechatron. 2006, 11, 17-26. [CrossRef]

36. Liu, Y.; Qin, D.; Jiang, H.; Zhang, Y. Shift control strategy and experimental validation for dry dual clutch transmissions. Mech. Mach. Theory 2014, 75, 41-53. [CrossRef]

37. Zhang, J.; Ni, Q.; Xu, L.; Liu, J. Shifting control strategy of a tractor AMT system. Aust. J. Mech. Eng. 2018, 16, 9-15. [CrossRef]

38. Xu, L.; Zhao, Y.; Zhou, Z.; Xi, Z.; Xing, M. Research on the law of AMT tractor clutch engagement at starting condition. Adv. Mater. Res. 2012, 482-484, 1418-1425. [CrossRef]

39. Dogan, O.; Karpat, F.; Yuce, C.; Kaya, N.; Yavuz, N.; Sen, H. A novel design procedure for tractor clutch fingers by using optimization and response surface methods. J. Mech. Sci. Technol. 2016, 30, 2615-2625. [CrossRef]

40. Zhong, Z.; Kong, G.; Yu, Z.; Chen, X.; Chen, X.; Xin, X. Concept evaluation of a novel gear selector for automated manual transmissions. Mech. Syst. Signal Process. 2012, 31, 316-331. [CrossRef]

41. Oh, J.Y.; Song, C.S. Development of Automated Mechanical Transmission Model to Evaluate TCU Control Logic. J. Korean Soc. Precis. Eng. 2010, 27, 118-126.

42. Horn, J.; Bamberger, J.; Michau, P.; Pindl, S. Flatness-based clutch control for automated manual transmissions. Control Eng. Pract. 2003, 11, 1353-1359. [CrossRef]

43. Siddique, A.A.; Kim, W.S.; Baek, S.Y.; Kim, Y.S.; Choi, C.H.; Kim, Y.J.; Park, J.K. Determination of PID coefficients for the ascending and descending system using proportional valve of a rice transplanter. J. Biosyst. Eng. 2018, 43, 331-341.

44. Sasane, A. An abstract Nyquist criterion containing old and new results. J. Math. Anal. Appl. 2010, 370, 703-715. [CrossRef]

(C) 2020 by the authors. Licensee MDPI, Basel, Switzerland. This article is an open access article distributed under the terms and conditions of the Creative Commons Attribution (CC BY) license (http://creativecommons.org/licenses/by/4.0/). 